\title{
Comprehensive Assessment of NR Ligand Polypharmacology by a Multiplex Reporter NR Assay.
}

\section{Alexander Medvedev}

Attagene

Matt Moeser

Attagene

Liubov Medvedeva

Attagene

Elena Martsen

Attagene

Alexander Granick

Attagene

Lydia Raines

Attagene

Kristen Gorman

Attagene

Benjamin Lin

Attagene

Ming Zeng

Attagene

Keith A. Houck

Environmental Protection Agency

Sergei S. Makarov ( $\sim$ smak@attagene.com )

Attagene

\section{Research Article}

Keywords: nuclear receptor, assay, reporter, multiplexed, polypharmacology, drug discovery, endocrine disrupting chemicals, NRome,

Posted Date: May 19th, 2021

DOl: https://doi.org/10.21203/rs.3.rs-478112/v1 
License: (c) (i) This work is licensed under a Creative Commons Attribution 4.0 International License. Read Full License

Version of Record: A version of this preprint was published at Scientific Reports on February 24th, 2022. See the published version at https://doi.org/10.1038/s41598-022-07031-8. 
Comprehensive assessment of NR ligand polypharmacology by a multiplex reporter NR assay.

Key words: nuclear receptor; assay; reporter; multiplexed; polypharmacology; drug discovery; endocrine disrupting chemicals; NRome;

Alexander Medvedev ${ }^{1}$, Matt Moeser ${ }^{1,2}$, Liubov Medvedeva ${ }^{1}$, Elena Martsen ${ }^{1}$, Alexander Granick $^{1}$, Lydia Raines ${ }^{1,3}$, Kristen Gorman ${ }^{1}$, Benjamin Lin $^{1}$, Ming Zeng ${ }^{1}$, Keith A.

Houck $^{4}$, Sergei S. Makarov ${ }^{1, *}$

${ }^{1}$ Attagene Inc, Research Triangle Park, North Carolina, USA

${ }^{2}$ Current address: UNC at Chapel Hill, Chapel Hill, North Carolina, USA

${ }^{3}$ Current address: Case Western Reserve University, Cleveland, $\mathrm{OH}$

${ }^{4}$ US Environmental Protection Agency, Research Triangle Park, North Carolina, USA

*Corresponding author: Sergei S. Makarov, Ph.D.

Attagene Inc, Research Triangle Park, North Carolina, USA

Direct 919-270-6031

smak@attagene.com (SSM) 
ABSTRACT. Nuclear receptors (NR) are ligand-modulated transcription factors that regulate multiple cell functions and thus represent excellent drug targets. However, due to a considerable NR structural homology, NR ligands often interact with multiple receptors. Here, we describe a multiplex reporter assay (the FACTORIAL NR) that enables parallel assessment of NR ligand activity across all 48 human NRs. The assay comprises one-hybrid GAL4-NR reporter modules transiently transfected into test cells. To evaluate the reporter activity, we assessed their RNA transcripts. We used a homogeneous RNA detection approach that afforded equal detection efficacy and permitted the multiplex detection in a single-well format. For validation, we examined a panel of selective NR ligands and polypharmacological agonists and antagonists of the progestin, estrogen, PPAR, ERR, and ROR receptors. The assay produced highly reproducible NR activity profiles $(r>0.96)$ permitting quantitative assessment of individual NR responses. The inferred EC50 values agreed with the published data. The assay showed excellent quality $\left(\left\langle Z^{\prime}\right\rangle=0.73\right)$ and low variability $(\langle\mathrm{CV}\rangle=7.2 \%)$. Furthermore, the assay permitted distinguishing direct and non-direct NR responses to ligands. Therefore, the FACTORIAL NR enables comprehensive evaluation of NR ligand polypharmacology. 


\section{INTRODUCTION}

The human NR superfamily comprises forty-eight ligand-modulated transcription factors that regulate transcriptional responses to endocrine stimuli ${ }^{1,2}$. NRs have ligandbinding domains (LBD) and DNA-binding domains (DBD) interacting with the target genes. Individual NRs recognize specific hormonal and metabolic ligands and regulate different metabolic functions ${ }^{1-3}$. The readily druggable NRs provide excellent drug targets. NR ligands comprise a large class of drugs used for multiple diseases and conditions, including inflammation, contraception, diabetes, and cancer ${ }^{4,5}$.

However, a considerable structural homology of NR proteins ${ }^{5}$ poses a significant challenge. Drug interactions with multiple NRs produce polypharmacological effects that can compromise safety; on the other hand, polypharmacological drugs can be highly efficacious $^{6,7}$. The proper evaluation requires assessing NR ligand effects on all human NRs, but tools for such comprehensive analysis are missing. The existing NR assays belong to two classes: the ligand-binding and the reporter gene assays ${ }^{8}$. The former permits high-content evaluation of NR ligand binding, but not the effects on NR activity. On the other hand, most reporter gene assays allow evaluating only a single NR response $^{8-10}$. Besides, the use of cell lines with stably integrated NR reporter constructs $^{9,10}$ is complicated by the gradual inactivation of the reporter expression ${ }^{11}$ and unpredictable effects of surrounding chromatin.

Here, we describe a multiplex reporter assay (the FACTORIAL NR) that enables the profiling of NR ligand activity across all human NRs. The assay makes use of onehybrid GAL4-NR reporter modules transiently transfected into test cells. Unlike the reporter gene assays, the FACTORIAL NR assay evaluates reporters' activity by their 
transcription rate. We have implemented a homogeneous detection approach ${ }^{12}$ that afforded parallel assessment of the multiple reporters with equal detection efficacy and in a single well of cells. We have described this approach in our previous publications and demonstrated its screening applications for detecting the endocrine disrupting activity in

chemicals and polluted water samples ${ }^{13,14}$. However, the prototypical trans-FACTORIAL assay of those studies covered only a fraction of the human NRome.

Here, we describe the comprehensive FACTORIAL NR encompassing all human NRs. We used a panel of selective NR ligands and a series of polypharmacological agonists and antagonists for assay validation ${ }^{13}$. Using the obtained NR activity profiles, we identified the NR targets and compared the inferred EC50 values with the reported data. Furthermore, we have characterized the quantitative assay parameters, including the specificity, variability, quality, and repeatability. We also explored the assay's utility for dissecting direct and indirect NR responses to the ligands.

\section{METHODS.}

Reagents. $17 \beta$-estradiol (CAT\# 10006315, CAS: 50-28-2, purity: $\geq 98 \%$ ), 4Hydroxytamoxifen (CAT\# 17308, CAS: 68392-35-8, purity: $\geq 98 \%$ ), Bexarotene (CAT\# 11571, CAS: 153559-49-0, purity: $\geq 98 \%$ ), Chenodeoxycholic acid (CAT\# 10011286, CAS: 474-25-9, purity: $\geq 95 \%$ ), Dexamethasone (CAT\# 11015, CAS: 50-02-2, purity:

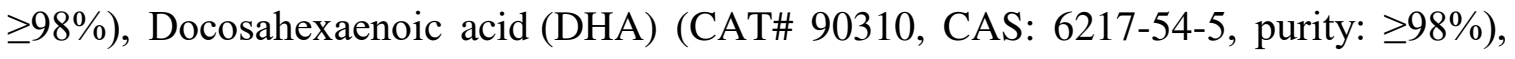
DY131 (CAT\# 17999, CAS: 95167-41-2, purity: $\geq 98 \%$ ), Eicosapentaenoic acid (EPA) (CAT\# 90110, CAS: 10417-94-4, purity: $\geq 98 \%$ ), Fexaramine (CAT\# 17369, CAS: 574013-66-4, purity: $\geq 98 \%$ ), GSK805 (CAT\# 9002444, CAS: 1426802-50-7, purity: 


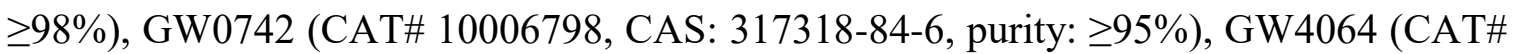
10006611, CAS: 278779-30-9, purity: $\geq 95 \%$ ), GW590735 (CAT\# 10009880, CAS: 622402-22-6, purity: $\geq 98 \%$ ), GW7647 (CAT\# 10008613, CAS: 265129-71-3, purity:

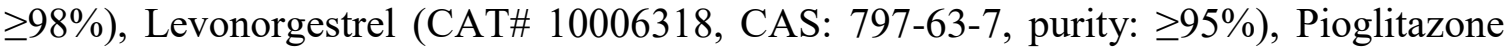

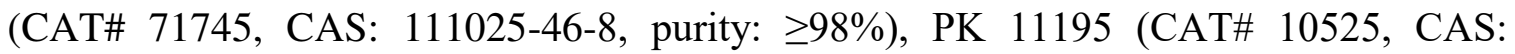
85532-75-8, purity: $\geq 98 \%$ ), Progesterone (CAT\# 15876, CAS: 57-83-0, purity: $\geq 98 \%$ ), T0901317 (CAT\# 71810, CAS: 293754-55-9, purity: $\geq 98 \%$ ), Troglitazone (CAT\# 71750, CAS: 97322-87-7, purity: $\geq 98 \%$ ), XCT790 (CAT\# 16035, CAS: 725247-18-7, purity: 298\%) were purchased from Cayman Chemical (Ann Arbor, Michigan 48108 USA).

5 $\alpha$-Dihydrotestosterone (CAT\# D-073, CAS: 521-18-6 , purity: $\geq 98 \%$ ), 9-cis-Retinoic acid (CAT\# R4643, CAS: 5300-03-8, purity: $\geq 98 \%$ ), Aldosterone (CAT\# A9477, CAS: 52-39-1, purity: $\geq 95 \%$ ), Azocyclotin (CAT\# 45335, CAS: 41083-11-8, purity: analytical

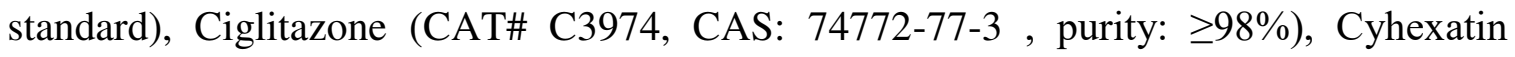
(CAT\# 45411, CAS: 13121-70-5, purity: analytical standard), Ethynodiol diacetate (CAT\# E7263, CAS: 297-76-7, purity: $\geq 98 \%$ ), Etonogestrel (CAT\# SML0356, CAS: 54048-10-1, purity: $\geq 98 \%$ ), Gestodene (CAT\# SML0292, CAS: 60282-87-3, purity: 298\%), GW501516 (CAT\# SML 1491, CAS: 317318-70-0, purity: $\geq 98 \%$ ), Medroxyprogesterone Acetate (CAT\# PHR1589, CAS: 71-58-9, purity: analytical standard), Norgestimate (CAT\# 94497, CAS: 35189-28-7, purity: analytical standard), Retinoic acid (CAT\# R2625, CAS: 302-79-4, purity: $\geq 98 \%$ ), Rifampicin (CAT\# R3501, CAS: 13292-46-1, purity: 297\%), Rosiglitazone (CAT\# R2408, CAS: 122320-73-4, purity: $\geq 98 \%$ ), Tributyltin chloride (CAT\# T50202, CAS: 1461-22-9, purity: $\geq 96 \%$ ), 3,3',5-Triiodo-L-thyronine (CAT\# T2877, CAS: 6893-02-3, purity: $\geq 95 \%$ ), Triphenyltin 


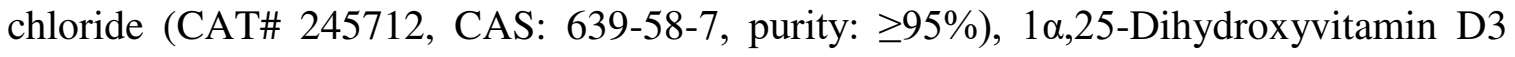
(CAT\# D1530, CAS: 32222-06-3, purity: $\geq 99 \%$ ) were purchased from Sigma-Aldrich (St. Louis, Missouri, USA). 6a-Fluorotestosterone (cat\# BML-S250-0005; CAS Number: 1597-68-8; Purity: $\geq 99.0 \%$ ) was from Enzo Life Sciences (Farmingdale, NY, USA). All chemicals were dissolved in dimethyl sulfoxide (DMSO), with the final concentration of $0.2 \% \mathrm{DMSO}$ in the cell growth media.

Cells. As in our previous studies, the FACTORIAL NR assay was conducted in the H19 clone (Attagene, NC, USA) of human hepatocellular carcinoma HepG2 cell line (ATCC \# HB-8065). The H19 clone had an elevated xenobiotic metabolizing activity ${ }^{12-14}$. Cells were propagated in a Dulbecco-modified essential culture medium (DMEM) Gibco (Waltham, MA, USA) supplemented with a $10 \%$ fetal bovine serum (FBS). The FACTORIAL NR assays were conducted in a low-serum media containing $1 \%$ charcoalstripped FBS (Hyclone, UT, USA).

The principle of FACTORIAL NR assay. The FACTORIAL NR is a modular assay comprising one-hybrid reporter modules for each human NR. An individual module has a GAL4-NR expression vector paired with a GAL4 reporter transcription unit (RTU) (Fig. 1A). The GAL4-NR vector provides constitutive expression of a chimeric GAL4-NR protein (a fusion of the NR LBD with GAL4 DBD). The RTU has a reporter sequence under the control of GAL4 DBD binding promoter. The GAL4-NR/RTU pair acts as a classic one-hybrid GAL4-NR reporter ${ }^{15,16}$. The GAL4-NR proteins transactivate the RTU reporter proportionate to the NR LBD activity.

To detect the FACTORIAL NR reporter modules, we profile the reporter RNA transcript using the homogeneous detection approach ${ }^{12}$. Under this approach, all RTUs 
have identical reporter sequences. To distinguish the RTU transcripts, the reporter sequences have the restriction tag (the HpaI site) placed at a different position (Fig. 1A).

The FACTORIAL NR detection entails RT-PCR amplification of reporter RNAs followed by HpaI digestion and detection of DNA fragments by capillary electrophoresis (Fig. 1B). The homogeneous design equalizes the multiple reporters detection efficacy, thereby abolishing the influence of experimental variables on the RNA profiles ${ }^{12}$.

The GAL4-NR/RTU modules. The assay comprises 50 reporter modules. There are forty-eight reporter GAL4-NR/RTU modules for each human NR. Their NR LBDs have the entire coding LBD sequences with the hinge domains. The GAL4-NR protein expression is under the control of a constitutive SV40 promoter.

To control for ligand effects on the GAL4 promoter, we used the GAL4 reporter module with the expression vector lacking an NR LBD. For internal normalization, we used the TATA module without an expression vector. Its reporter sequence was under the control of a minimal TATA box promoter.

Validating the reporter modules. Prior to assembling the multiplex assay, we tested the functionality of individual reporter modules. All GAL4-NR expression vectors were sequence-verified. To assess the basal activity and NR ligand responsiveness, we used a traditional reporter gene assay with the secreted alkaline phosphatase (SEAP) The GAL4NR vectors were transiently transfected along with the GAL4-SEAP reporter plasmid containing the SEAP cDNA. The SEAP activity was detected in cell growth medium following vendor's protocol (Thermo Fisher Scientific, USA).

To test the constructs with unknown specific NR ligands, we used two-hybrid cofactor interaction assays ${ }^{17}$. That is, we assessed GAL4-NR responses to co-expressed 
NR coactivators (RIP140-VP16) and corepressors (NCOR-VP16 and SMRT-VP16). For the GAL4- SHP (which has no NR cofactors), we verified its expression by RT-PCR. The Table S1 and supplementary Fig. S1 summarize the test results.

The assay workflow. The assay was done following the previously described protocols ${ }^{12}$ (Fig. 1B). The reporter modules were transiently transfected into separate pools of HepG2 cells using the TransIT-LT1 reagent (Mirus). Twenty-four hours later, cells were trypsinized and mixed in an equal proportion. The cell mix was plated into 12-well plates in a $10 \%$ FBS growth medium. Each well represented an individual FACTORIAL NR assay. After the plating, cells were incubated overnight in a fresh low-serum (1\% FBS) growth medium and treated with tested compounds for $24 \mathrm{~h}$.

Total RNA was isolated using the PureLink RNA isolation kit (Invitrogen) and processed as described ${ }^{12}$. Briefly, total RNA was reversely transcribed and amplified by a single PCR reaction tube using one pair of RTU primers. The PCR products were labeled in an extension reaction with a 6-Fam-labeled primer. After digestion with the HpaI enzyme, the DNA fragments were resolved by DNA Genetic Analyzer 3130xl (ABI).

Data Analysis. The output of the FACTORIAL NR assay is the CE electrophoregram that mirrors the GAL4-NR activity. To normalize CE profiles by different assays, we used the TATA module signals. Each tested NR ligand was assessed by three independent FACTORIAL NR assays, and the NR activity profiles were calculated as an average of the three replicates. To characterize NR ligand activity, we used differential NR activity profiles calculated by dividing the NR activity values for ligand-treated cells by those in vehicle-treated cells. 
Statistical analysis. To compare NR activity profiles, we used the Pearson correlation coefficient $(r)^{12}$. The significance of individual NR responses was evaluated by Student's t-test for the average values of three replicate assays. To assess the intraassay variability of individual NR endpoints, we used the coefficient of variation (CV) for multiple replicate assays within a single experiment using the formula below.

$$
\mathrm{CV}=(\text { Standard Deviation/Mean induction }) * 100
$$

As the aggregate intraassay variability $\langle\mathrm{CV}\rangle$, we used average $\mathrm{CV}$ values across all significant NR responses. To assess assay quality, we used Z'-factor values for individual NR endpoints ${ }^{18}$. The baseline activity in vehicle-treated cells and the activity in stimulated cells provided the negative and positive control values, respectably. As the aggregate assay quality $\left\langle Z^{\prime}\right\rangle$, we used the average of $Z^{\prime}$ - factor values across all significant NR endpoints. To calculate EC50 values, we interpolated the concentrationresponse curves by the curve-fitting algorithms of the 4-Parameter Logistic (4PL) model16, using the DRC package (v.2.5-12) ${ }^{19}$ of R software (v. 3.2.5) ${ }^{20}$, and the SciPy package of Python (v3.62.). The NR activity profile heatmaps were generated using the Matplotlib and Seaborn modules of Python.

\section{RESULTS.}

The FACTORIAL NR detection parameters.

The baseline NR activity profile. In the absence of stimulation, the activity of most GAL4-NRs was within the 10 -fold range of the GAL4 reporter. The ROR $\alpha, \beta, \gamma$, 
RAR $\alpha, \beta$, ERR $\alpha, \gamma$, CAR, and SF-1 reporters had a higher activity (suppl. Fig. S2) This high constitutive activity may stem from the presence of endogenous NR ligands or activation of signaling pathways potentiating NR activity ${ }^{21}$.

The specificity. We used a panel of physiological NR ligands for the vitamin D (VDR), progesterone (PR), estrogen (ER), farnesoid X (FXR), and thyroid hormone (THR) receptors (Fig. 2A). The assay detected specific NR responses, whereas irrelevant NR responses were within the error margin $(<+/-3 \mathrm{SD})$. Some ligands had induced multiple responses (e.g., PXR activation by progesterone and chenodeoxycholic acid), consistent with the reported data ${ }^{22,23}$.

Fig. 2B shows NR activity profiles for synthetic NR agonists of androgen (AR), pregnane X (PXR), peroxisome proliferator-activated receptor gamma (PPAR $\gamma$ ), glucocorticoid (GR), and liver X (LXR) receptors. The profiles were entirely consistent with the reported data. For example, in addition to the primary activity at the LXR $\alpha$ and LXR $\beta$, LXR agonist T0901317 had significantly activated the PXR ${ }^{24}$. Dexamethasone significantly activated its primary target GR and the mineralocorticoid (MR) receptor ${ }^{25,26}$. More profiles for specific NR ligands are shown by supplementary Fig. S3. Therefore, the FACTORIAL NR assay specifically responded to the selective ligands.

The assay variability and quality. To assess the intraassay variability, we used the CV coefficient for multiple replicate assays within a single experiment. The CV values for the prototypical ligands (as shown by Figs. 2A-B) varied from 5.04\% to 10.9\%, with an average value of $7.23 \%$.

The assay quality was assessed by the Z'-factor that characterizes the separation of the induced and baseline reporter activity and the likelihood of false 
positives/negatives ${ }^{18}$. To calculate $Z^{\prime}$ values for individual endpoints, we used data of three independent replicate assays of the same experiment. The $\mathrm{Z}$ ' factor values for Fig. $2 \mathrm{~A}, \mathrm{~B}$ data were in the range from 0.52 to 0.82 with an average value of 0.73 . That exceeds the excellent quality criterion $\left(Z^{\prime}>0.5\right)^{18}$.

The reproducibility. For the reproducibility assessment, we compared the NR activity profile for polyvalent NR ligands from different experiments. As a quantitative measure, we used the Pearson correlation coefficient $(r)$. As an example, Fig. 2C shows the signatures for a synthetic RXR agonist bexarotene ${ }^{27}$. The NR activity profiles were faithfully reproduced $(\mathrm{r}=0.991)$ in experiments performed over several months. The signature endpoints (RXRs, Nur77, and NURR1) were in agreement with others' data ${ }^{28,29}$.

Assessing NR ligand-receptor interactions. Using the FACTORIAL NR in a concentration-response format, we assessed the EC50 values for ligand-receptor interactions. The concentration-response data for selective NR ligands fitted the classic Hill equation sigmoid curves (Fig. 3). More concentration-response data are shown by supplementary Fig. S4. The inferred EC50 values agreed with the published data by others (Table 1). Therefore, the FACTORIAL NR permitted accurate quantitative evaluation of ligand-receptor interactions.

Examining NR antagonists. The rapid turnover of reporter RNA makes the FACTORIAL NR assay particularly well-suited for detecting inhibited NR responses to NR antagonists. Fig. 4A shows the NR activity profiles for ERR $\alpha$, ROR $\gamma$, and ER antagonists. The high basal activity of ERR $\alpha$ and ROR $\gamma$ reporters (suppl. Fig. S2) 
allowed assessing their antagonists without additional stimulation. The NR activity profiles agreed with the literature data on these antagonists. The single NR response to ROR $\gamma$ antagonist GSK805 reflected its primary activity ${ }^{30}$ (Fig. 4Aa). The ERR $\alpha$ antagonist XCT79027 had inhibited the primary target (ERR $\alpha)$ and activated the PPAR $\gamma$ (Fig. 4Ab). The PPAR $\gamma$ response may be explained by XCT790 effects on PPAR $\gamma$ coactivator 1-alpha (PGC-1 $\alpha)^{31}$.

The ER antagonist 4-hydroxytamoxifen (4-HT) is the major active metabolite of tamoxifen $^{32}$. Since ER reporters had low basal activity (suppl. Fig. S3), we stimulated cells with ER agonist $17 \beta$ estradiol (E2). The NR activity profile for 4-HT showed an inhibition of $\mathrm{ER} \alpha$ and $\mathrm{ER} \beta$ and $\mathrm{ERR} \gamma(\mathrm{Fig}$. 4Ac). The ERR $\gamma$ response to 4-HT was consistent with the reported data ${ }^{33}$.

Using the assay in a concentration-response format, we determine EC50 values for the NR antagonists (Fig. 4Ba-c). The inferred values were in agreement with the literature data (Table 1).

These results demonstrate excellent quality ( $Z$ ' factor), low intraassay variability (CV), high reproducibility ( $\mathrm{r}$ ), and the robustness of the FACTORIAL NR assay. Furthermore, these data show the assay's capability for evaluating both NR agonists and antagonists.

Examining polypharmacological NR ligands. We used a diverse panel of polypharmacological PR and PPAR ligands, including drugs, nutritionals, and environmental chemicals. 
PR agonists. Progestins are synthetic analogs of the hormone progesterone, widely used in contraception pills and hormone replacement therapy ${ }^{34}$. The primary progestin target is the PR receptor, but they have activities at other NRs, translating in various clinical effects $^{35,36}$.

The evaluated progestins included etonogestrel (ETG), gestodene (GST), medroxyprogesterone acetate (MEDA), norgestimate (NGS), levonorgestrel (LVG), ethynodiol diacetate (ETD). The Fig. 5 heatmap exemplifies progestins' NR activity profiles (for more data see suppl. Fig. S5A-B). The activity profiles were faithfully reproduced ( $r>0.96)$ in experiments conducted over a several-month period (Fig. 6).

The inferred EC50 values for the on-target progestins' activity at PR varied from $0.048 \mathrm{nM}$ to $0.95 \mathrm{nM}$ (Fig. 7A,B). The common off-target effects were on the AR, ER, GR, and PXR receptors, consistent with the literature ${ }^{35-38}$, (Fig. 5). These effects varied. For example, NGS had a weak activity at the AR and GR; MEDA showed no estrogenic activity; ETD activated the FXR receptor (Fig. 5 and suppl. Fig. S5B).

Using the assay in competitive mode, we examined some off-target activity mechanisms. As an example, we used levonorgestrel (LVG), which had the off-target activity at the PXR, AR, ER $\alpha$, and ER $\beta$ (Fig. 5). These responses could stem from the direct ligand binding or from activation of cellular pathways that potentiate the NR activity. To distinguish between these possibilities, we assessed these responses in the presence NR antagonists. The ER antagonist 4-HT. had inhibited ER $\alpha$ and ER $\beta$ activation, but not other NR responses (Fig. 7Ca). (For other progestins' data see suppl. Fig. S7). Akin to that, AR antagonist flutamide selectively inhibited LVG effects at the AR (Fig. 7Cb). Therefore, ER and AR activation were a direct effect of LVG binding. 
PPAR agonists. We used PPAR agonists from four classes: nutritional ligands (omega-3 fatty acids); pharmacological PPAR $\gamma$ agonists (glitazones); selective PPAR $\alpha$ and PPAR $\delta$ agonists; and environmental ligands (organotins). We used high concentrations to capture the maximal range of off-target activities (Fig. 8A). Each class of PPAR ligands produced distinct clusters of signatures.

One cluster comprised signatures for the most common omega-3 acids, the eicosapentaenoic acid (EPA) and docosahexaenoic acid (DHA) ${ }^{39}$. The activity profiles comprised PPAR $\gamma$ and PPAR $\alpha$ responses, the hallmark omega- 3 acids activities ${ }^{40}$.

The pharmacological PPAR agonist cluster had signatures for antidiabetic drugs pioglitazone, ciglitazone, troglitazone, and rosiglitazone. Consistent with their primary activity $^{41}$, all glitazones induced PPAR $\gamma$ activation. The common PXR response to glitazones also agreed with the published data ${ }^{42}$. Interestingly, pioglitazone also activated PPAR $\alpha$; we observed this effect in multiple experiments and further confirmed it in the competitive experiments (see Fig. 8Ca).

The third signature cluster comprised selective agonists of PPAR $\alpha$ (GW59073540 and GW764741) and PPARS (GW074242 and GW50151643). At a high $(5 \mu \mathrm{M})$ concentration, all compounds activated $\operatorname{PPAR} \alpha, \delta$, and $\gamma$, and PXR. We also detected a weak estrogenic activity of GW501516. At low concentrations, GW7647 and GW0742 selectively activated PPAR $\alpha$ and PPAR , respectively (Fig. 8B), which was consistent with their selectivity ${ }^{43,44}$. The inferred EC50 values for these compounds agreed with the literature data (Table 1).

The fourth signature cluster comprised widely used tin-containing environmental contaminants and potential obesogens, organotins ${ }^{45}$. Consistent with the literature 
data $^{45,46}$, the NR activity profiles for organotins showed activation of PPAR $\gamma$, NURR1, and RXR $\alpha, \beta$, and $\gamma$ (Fig. 8A and suppl. Fig. S6). One organotin (tributyltin chloride) also activated PPAR $\delta$ and PXR.

To examine the underlying mechanisms for PPAR ligands' activity, we used the assay in a competitive mode (Fig. 8C and suppl. Fig. S8). T0070907 is a PPAR ligand selectively inhibiting PPAR $\gamma$ at low concentrations ${ }^{47}$ and all PPARs at high concentrations. The addition of T0070907 had inhibited PPAR $\gamma$ and PPAR $\alpha$ responses to pioglitazone (Fig. 8Ca) and PPAR $\delta$ response to tributyltin (TBT) (Fig. 8Cb). Therefore, the PPAR responses to pioglitazone and TBT stemmed from the ligand binding.

The addition of RXR antagonist UVI $3003^{48}$ had inhibited RXRs and NURR1 responses to tributyltin (TBT) (Fig. 8Cc). Therefore, RXR activation by TBT was due to ligand binding, whereas NURR1 activation was RXR-dependent, probably through the NURR1-RXR dimerization ${ }^{49}$.

Summarily, these results demonstrate that the FACTORIAL NR assay permits comprehensive evaluation of NR ligand polypharmacology. The assay allowed for clearcut identification of their targets and the EC50 values and provided valuable mechanistic insights into their activity.

\section{DISCUSSION.}

Described here the FACTORIAL NR assay expands the toolbox of NR evaluation technologies. Currently, reporter gene assays are the gold standard for NR ligand evaluation ${ }^{8}$. However, most of these assays evaluate only a single NR response. Screening NR ligands across multiple receptors necessitates large assay panels. That 
requires protracted assay development, time, and expense. Moreover, these screens may not always be appropriately controlled, complicating the analysis across experimental variables $^{50,51}$.

The transcription-based detection obviates the low-content limitation of reporter gene assays. The homogeneous RNA detection approach enabled parallel assessment of multiple reporters in a single-well format. Furthermore, this approach has equalized detection efficacy across reporters, thereby abolishing the influence of variable experimental conditions ${ }^{12}$. To avoid the unpredictable effects of host genome on the reporter transcription and to prevent reporter expression inactivation over time ${ }^{52}$, we used transient transfection of reporter modules.

The inherent robustness translated into excellent assay quality $\left(<Z^{\prime}>=0.73>\right.$ and low intraassay variability $(\langle\mathrm{CV}\rangle=7.2 \%)$. The obtained NR activity profiles were faithfully reproduced $(r>0.96)$ in experiments conducted over several-month period. These signatures afforded comprehensive evaluation of polypharmacological NR ligands through the identification of their NR targets.

We showed that the FACTORIAL NR provided quantitative evaluation of ligandreceptor interactions. Importantly, the inferred EC50 values agreed with the published data. It should be noted that the EC50 estimates by different groups often differed by orders of magnitude (e.g., see Table 1). That may be explained by the differences in the reporter assays and experimental conditions. In this regard, a distinct advantage of FACTORIAL NR assay is that it provides parallel evaluation of EC50 values for multiple receptors, thereby minimizing the variability. 
The RNA-based detection by the FACTORIAL NR has another important advantage. The rapid turnover of reporter transcripts facilitates detecting inhibited NR responses. That allowed assessing EC50 values for the multiple targets of polypharmacological NR antagonists.

Importantly, the FACTORIAL NR provides mechanistic insights into NR ligand activity. We showed that the assay permitted distinguishing between direct and indirect effects of polypharmacological ligands on their NR targets (Fig. 7C and 8C).

Previously, we described applications of our prototype FACTORIAL NR (a.k.a. trans-FACTORIAL) assay for assessing environmental chemicals ${ }^{14}$, water pollution ${ }^{13}$, and NR drugs ${ }^{53}$. However, the prototype assay covered only a fraction of human NRs. Presented here FACTORIAL NR enables profiling NR ligands across the entire human NRome thus permitting the comprehensive evaluation of environmental and pharmacological NR ligands.

An inherent limitation of any NR assay for drug evaluation is that they focus exclusively on NR responses. To assess NR-independent mechanisms, we have developed another multiplex reporter assay, the FACTORIAL TF (a.k.a. cisFACTORIAL), that permits assessing the activity of 46 TF families in living cells ${ }^{12,14}$. We showed previously that TF activity profiles (TFAP) of compounds provided valuable information about their cellular targets ${ }^{54}$. We found specific TFAP signatures for perturbagens of biological process or cell systems. Remarkably, perturbagens of the same process produced identical TFAP signatures, regardless of where and how they interfered $^{54}$. We found such specific signatures for the compounds producing mitochondria malfunction, DNA damage, cytoskeleton disruption, and HDAC and 
$\mathrm{Ub} /$ proteasome inhibition ${ }^{54}$. Therefore, NR ligand evaluation by a combination of the

FACTORIAL NR and FACTORIAL TF assays permits assessing their effects at the NRome and NR-independent bioprocesses and cell systems.

\section{REFERENCES.}

1. Francis, G. A., Fayard, E., Picard, F. \& Auwerx, J. Nuclear Receptors and the Control of Metabolism. Annu. Rev. Physiol. 65, 261-311 (2003).

2. Evans, R. M. \& Mangelsdorf, D. J. Nuclear Receptors, RXR, and the Big Bang. Cell 157, 255-66 (2014).

3. Alexander, S. P. H. et al. The Concise Guide to PHARMACOLOGY 2013/14: nuclear hormone receptors. Br. J. Pharmacol. 170, 1652-75 (2013).

4. Gronemeyer, H., Gustafsson, J.-A. \& Laudet, V. Principles for modulation of the nuclear receptor superfamily. Nat. Rev. Drug Discov. 3, 950-64 (2004).

5. Burris, T. P. et al. Nuclear receptors and their selective pharmacologic modulators. Pharmacol. Rev. 65, 710-78 (2013).

6. Hopkins, A. L. Network pharmacology: the next paradigm in drug discovery. doi:10.1038/nchembio.118

7. Anighoro, A., Bajorath, J. \& Rastelli, G. Polypharmacology: Challenges and Opportunities in Drug Discovery. J. Med. Chem. 57, 7874-7887 (2014).

8. Raucy, J. L. \& Lasker, J. M. Current in vitro high throughput screening approaches to assess nuclear receptor activation. Curr. Drug Metab. 11, 806-14 (2010).

9. Willemsen, P. et al. Use of reporter cell lines for detection of endocrine-disrupter 
activity. Anal. Bioanal. Chem. 378, 655-63 (2004).

10. Grimaldi, M. et al. Reporter cell lines to evaluate the selectivity of chemicals for human and zebrafish estrogen and peroxysome proliferator activated $\hat{\mathrm{I}}^{3}$ receptors. Front. Neurosci. 9, 212 (2015).

11. Pikaart, M. J., Recillas-Targa, F. \& Felsenfeld, G. Loss of transcriptional activity of a transgene is accompanied by DNA methylation and histone deacetylation and is prevented by insulators. Genes Dev. 12, 2852-62 (1998).

12. Romanov, S. et al. Homogeneous reporter system enables quantitative functional assessment of multiple transcription factors. Nat Methods 5, 253-260 (2008).

13. Blackwell, B. R. et al. Potential Toxicity of Complex Mixtures in Surface Waters from a Nationwide Survey of United States Streams: Identifying in Vitro Bioactivities and Causative Chemicals. Environ. Sci. Technol. 53, 973-983 (2019).

14. Martin, M. T. et al. Impact of environmental chemicals on key transcription regulators and correlation to toxicity end points within EPA's ToxCast program. Chem Res Toxicol 23, 578-590 (2010).

15. Hollenberg, S. M. \& Evans, R. M. Multiple and cooperative trans-activation domains of the human glucocorticoid receptor. Cell 55, 899-906 (1988).

16. Webster, N. J., Green, S., Jin, J. R. \& Chambon, P. The hormone-binding domains of the estrogen and glucocorticoid receptors contain an inducible transcription activation function. Cell 54, 199-207 (1988).

17. Tyree, C. M. \& Klausing, K. The Mammalian Two-Hybrid Assay for Detection of Coactivator-Nuclear Receptor Interactions. in Novel Anticancer Drug Protocols 175-184 (Humana Press, 2003). doi:10.1385/1-59259-380-1:175 
18. Zhang, J.-H., Chung \& Oldenburg. A Simple Statistical Parameter for Use in Evaluation and Validation of High Throughput Screening Assays. J. Biomol. Screen. 4, 67-73 (1999).

19. Strebig, J. C. Package 'drc' Title Analysis of Dose-Response Curves. (2016).

20. R: The R Project for Statistical Computing. Available at: https://www.rproject.org/. (Accessed: 14th April 2021)

21. Mukherjee, S. \& Mani, S. Orphan nuclear receptors as targets for drug development. Pharmaceutical Research 27, 1439-1468 (2010).

22. Kliewer, S. A. et al. An Orphan Nuclear Receptor Activated by Pregnanes Defines a Novel Steroid Signaling Pathway. Cell 92, 73-82 (1998).

23. Carazo, A. et al. Acetylated deoxycholic (DCA) and cholic (CA) acids are potent ligands of pregnane X (PXR) receptor. Toxicol. Lett. 265, 86-96 (2017).

24. Mitro, N., Vargas, L., Romeo, R., Koder, A. \& Saez, E. T0901317 is a potent PXR ligand: Implications for the biology ascribed to LXR. FEBS Lett. 581, 1721-1726 (2007).

25. Grossmann, C. et al. Transactivation via the human glucocorticoid and mineralocorticoid receptor by therapeutically used steroids in CV-1 cells: a comparison of their glucocorticoid and mineralocorticoid properties. Eur. J. Endocrinol. 151, 397-406 (2004).

26. Sedlák, D., Paguio, A. \& Bartůněk, P. Two panels of steroid receptor luciferase reporter cell lines for compound profiling. Comb. Chem. High Throughput Screen. 14, 248-66 (2011).

27. Lowe, M. N. \& Plosker, G. L. Bexarotene. Am. J. Clin. Dermatol. 1, 245-50; 
discussion 251-2 (2000).

28. McFarland, K. et al. Low dose bexarotene treatment rescues dopamine neurons and restores behavioral function in models of Parkinson's disease. ACS Chem. Neurosci. 4, 1430-8 (2013).

29. Giner, X. C., Cotnoir-White, D., Mader, S. \& Lévesque, D. Selective ligand activity at Nur/retinoid $\mathrm{X}$ receptor complexes revealed by dimer-specific bioluminescence resonance energy transfer-based sensors. FASEB J. 29, 4256-67 (2015).

30. Xiao, S. et al. Small-molecule ROR $\gamma t$ antagonists inhibit $\mathrm{T}$ helper 17 cell transcriptional network by divergent mechanisms. Immunity 40, 477-89 (2014).

31. Willy, P. J. et al. Regulation of PPARgamma coactivator 1alpha (PGC-1alpha) signaling by an estrogen-related receptor alpha (ERRalpha) ligand. Proc. Natl. Acad. Sci. U. S. A. 101, 8912-7 (2004).

32. Murphy, C. S., Langan-Fahey, S. M., McCague, R. \& Jordan, V. C. Structurefunction relationships of hydroxylated metabolites of tamoxifen that control the proliferation of estrogen-responsive T47D breast cancer cells in vitro. Mol. Pharmacol. 38, (1990).

33. Coward, P., Lee, D., Hull, M. V \& Lehmann, J. M. 4-Hydroxytamoxifen binds to and deactivates the estrogen-related receptor gamma. Proc. Natl. Acad. Sci. U. S. A. 98, 8880-4 (2001).

34. Schindler, A. E. et al. Classification and pharmacology of progestins. Maturitas 46 Suppl 1, S7-S16 (2003).

35. Runnalls, T. J., Beresford, N., Losty, E., Scott, A. P. \& Sumpter, J. P. Several 
Synthetic Progestins with Different Potencies Adversely Affect Reproduction of Fish. Environ. Sci. Technol. 47, 2077-2084 (2013).

36. Louw-du Toit, R., Perkins, M. S., Hapgood, J. P. \& Africander, D. Comparing the androgenic and estrogenic properties of progestins used in contraception and hormone therapy. Biochem. Biophys. Res. Commun. 491, 140-146 (2017).

37. Jordan, V. C., Jeng, M. H., Catherino, W. H. \& Parker, C. J. The estrogenic activity of synthetic progestins used in oral contraceptives. Cancer 71, 1501-1505 (1993).

38. Koubovec, D., Ronacher, K., Stubsrud, E., Louw, A. \& Hapgood, J. P. Synthetic progestins used in HRT have different glucocorticoid agonist properties. Mol. Cell. Endocrinol. 242, 23-32 (2005).

39. Davidson, M. H. Omega-3 fatty acids: new insights into the pharmacology and biology of docosahexaenoic acid, docosapentaenoic acid, and eicosapentaenoic acid. Curr. Opin. Lipidol. 24, 467-74 (2013).

40. Calder, P. C. Mechanisms of Action of (n-3) Fatty Acids. J. Nutr. 142, 592S-599S (2012).

41. Hauner, H. The mode of action of thiazolidinediones. Diabetes. Metab. Res. Rev. 18 Suppl 2, S10-5

42. Singh, S. K., Yende, A. S., Ponnusamy, K. \& Tyagi, R. K. A comprehensive evaluation of anti-diabetic drugs on nuclear receptor PXR platform. Toxicol. Vitr. 60, 347-358 (2019).

43. Brown, P. J. et al. Identification of a subtype selective human PPARalpha agonist through parallel-array synthesis. Bioorg. Med. Chem. Lett. 11, 1225-7 (2001). 
44. Sznaidman, M. L. et al. Novel selective small molecule agonists for peroxisome proliferator-activated receptor delta (PPARdelta)--synthesis and biological activity. Bioorg. Med. Chem. Lett. 13, 1517-21 (2003).

45. Grün, F. \& Blumberg, B. Environmental Obesogens: Organotins and Endocrine Disruption via Nuclear Receptor Signaling. Endocrinology 147, s50-s55 (2006).

46. Grün, F. et al. Endocrine-Disrupting Organotin Compounds Are Potent Inducers of Adipogenesis in Vertebrates. Mol. Endocrinol. 20, 2141-2155 (2006).

47. Lee, G. et al. T0070907, a selective ligand for peroxisome proliferator-activated receptor gamma, functions as an antagonist of biochemical and cellular activities. J. Biol. Chem. 277, 19649-57 (2002).

48. Zhu, J. et al. The unexpected teratogenicity of RXR antagonist UVI3003 via activation of PPAR $\gamma$ in Xenopus tropicalis. Toxicol. Appl. Pharmacol. 314, 91-97 (2017).

49. Wallén-Mackenzie, Å. et al. Nurr1-RXR heterodimers mediate RXR ligandinduced signaling in neuronal cells. Genes Dev. 17, 3036-3047 (2003).

50. Gray, L. E. et al. Endocrine Screening Methods Workshop report: detection of estrogenic and androgenic hormonal and antihormonal activity for chemicals that act via receptor or steroidogenic enzyme mechanisms. Reprod. Toxicol. 11, 719 50 (1997).

51. Rotroff, D. M. et al. Using in vitro high throughput screening assays to identify potential endocrine-disrupting chemicals. Environ. Health Perspect. 121, 7-14 (2013).

52. Pikaart, M. J., Recillas-Targa, F. \& Felsenfeld, G. Loss of transcriptional activity 
of a transgene is accompanied by DNA methylation and histone deacetylation and is prevented by insulators. Genes Dev. 12, 2852-2862 (1998).

53. Whitehead, G. S. et al. Therapeutic suppression of pulmonary neutrophilia and allergic airway hyperresponsiveness by a ROR $\gamma \mathrm{t}$ inverse agonist. JCI insight $\mathbf{5}$, (2019).

54. Medvedev, A. et al. Evaluating biological activity of compounds by transcription factor activity profiling. Sci. $A d v .4$, eaar4666 (2018).

\section{ACKNOWLEDGEMENTS}

This work was supported by the NIH/NIGMS grant 1R44GM125469 to Attagene. The views expressed in this paper are those of the authors and do not necessarily reflect the statements, opinions, views, conclusions, or policies of the U.S. Environmental Protection Agency.

\section{AUTHOR CONTRIBUTIONS STATEMENT.}

A.M. and S.S.M. are co-inventors of the Factorial technology. A.M. and S.S.M. designed and supervised experiments, analyzed and interpreted data. M.M. constructed the GAL4NR reporter modules and performed experiments. A.M., L.M., E.M., A.G., L.R., M.Z., K.G., and B.L. performed experiments. E.M. performed quality control, S.S.M, A.M. and K.A.H. interpreted data; S.S.M. wrote the manuscript with contribution of A.M. and K.A.H. 


\section{CONFLICT OF INTERESTS STATEMENT.}

S.S.M., A.M., E.M., L.M., and M.M. are shareholders of Attagene. Inc.

\section{DATA AVAILABILITY.}

The authors declare that the all data needed to support the conclusions of this study are available in the paper and the supplementary information. The raw data are available from the corresponding author upon reasonable request.

\section{FIGURE LEGENDS.}

Figure 1. The FACTORIAL NR assay. A. The GAL4-NR/RTU reporter module. The module comprises a GAL4-NR expression vector paired with a GAL4 reporter transcription unit (RTU). The module acts as a one-hybrid reporter construct producing RTU transcripts proportionate to NR LBD transcriptional activity. The RTU reporter sequence contains a restriction tag (the HpaI site). B. The detection flowchart. The GAL4-NR/RTU modules are transiently transfected into separate pools of test cells. Transfected cells are mixed and plated into assay plate wells. After stimulation, total cellular RNA is amplified by RT-PCR, labeled by a fluorescent label, cut by HpaI enzyme and separated by capillary electrophoresis (CE). The CE profile mirrors the GAL4-NR activity.

Figure 2. Profiling NR ligand activity by the FACTORIAL NR. The NR activity profiles for physiological (A) and synthetic (B) ligands. The NR activity profiles show the GAL4-NR activity in stimulated cells normalized by that in vehicle-treated cells. Bar 
graphs show NR activity fold-changes on a linear scale and radial graphs show logtransformed values. Each profile is an average of three independent FACTORIAL NR assays. Significant NR responses are marked $\left({ }^{*} * \mathrm{P}<0.005 ;{ }^{*} \mathrm{P}<0.05\right)$. The $\mathrm{Z}$ '- score and $\mathrm{CV}$ values for individual responses are average of three independent assays. $\mathbf{C}$. The reproducibility. NR activity profiles for RXR agonist bexarotene in two independent experiments. Each profile is an average of three independent FACTORIAL NR assays. The profile similarity calculated as Pearson correlation coefficient $r$. The Z'- score and $\mathrm{CV}$ values for individual responses are average of three independent assays in one experiment. The aggregate $\left\langle\mathrm{Z}^{\prime}\right\rangle$ and $\langle\mathrm{CV}\rangle$ values are average across all significant responses.

Figure 3. Assessing the EC50 values for ligand-receptor interactions. The concentration-response values for the ligands were interpolated by the Hill equation. The inferred EC50 values are average values of three independent FACTORIAL NR assays.

Figure 4. Assessing NR antagonists by the FACTORIAL NR assay. A. The NR activity profiles for $\operatorname{ROR} \gamma(\mathbf{a}), \mathrm{ERR} \alpha(\mathbf{b})$, and ER (c) antagonists after a 24-hr incubation. The log-transformed fold-changes of NR activity in antagonist- vs. vehicle-treated cells are shown. (c) To assess ER antagonist 4-HT, cells were stimulated with ER agonist 17ßestradiol (E2). The differential NR activity profile (c) shows NR activity changes in cells treated with the combination of E2/4-HT vs. that in E2-treated cells. The a-c profiles are average of three independent replicate FACTORIAL NR assays. B. The concentrationresponses of the primary NR targets of $\operatorname{ROR} \gamma(\mathbf{a}), \operatorname{ERR} \alpha(\mathbf{b})$, and ER (c) antagonists. The 
responses show the percentage of the baseline activity in vehicle-treated (a,b). or (c) E2stimulated cells. The inferred EC50 values are average data of three independent FACTORIAL NR assays.

Figure 5. Assessing the polypharmacology of progestins. The heatmap shows NR activity profiles for progestins after a $24 \mathrm{~h}$ incubation with indicated concentrations. The fold-induction NR activity values in progestin- vs. vehicle-treated cells are shown. Abbreviations: ETG: etonogestrel; GST: gestodene; MEDA: medroxyprogesterone acetate; NGS: norgestimate; $L V G$ : levonorgestrel; ETD: ethynodiol diacetate; PRG: progesterone.

Figure 6. The reproducibility of progestins' NR activity profiles. The NR data of two independent experiments are shown. Each profile is an average of three independent replicate FACTORIAL NR assays. The similarity of NR activity profiles is calculated as the Pearson correlation coefficient $r$.

Figure 7. Evaluating the NR activity of progestins. A. The concentration-response of progestins' primary target (the PR). The data shown as the percentage of the maximal PR activation by the progestins. Average data of three independent replicate FACTORIAL NR assays are shown. B. The inferred EC50 values for the primary progestin activity. C. A competitive mode assay to assess off-target activity mechanisms. The graphs show logtransformed NR activity fold-changes (in progestin- vs. vehicle-treated cells) after a 24-h treatment with LVG. Blue line shows the NR activity profile for LVG. Red line: the NR 
activity profile for LVG in the presence of ER inhibitor 4-HT (a) or AR inhibitor FT (b). Each is the average profile of three independent replicate FACTORIAL NR assays.

Fig. 8. Assessing the polypharmacology of PPAR agonists. A. NR activity profiles after a $24 \mathrm{~h}$ incubation with indicated concentrations of PPAR ligands. The heatmap shows fold-induction NR activity values in stimulated vs. vehicle-treated cells. Each profile is an average of three independent replicate FACTORIAL NR assays. Abbreviations: EPA, eicosapentaenoic acid; DHA, docosahexaenoic acid; Cig, ciglitazone; Pio, pioglitazone; Trog, troglitazone; Rosi, rosiglitazone; TBT, tributyltin; $T P T$, triphenyltin; $A C T$, azocyclotin; $C Y H$, Cyhexatin. Organotins were used at $0.1 \mu \mathrm{M}$; all other inducers at $5 \mu \mathrm{M}$. B. Concentration-response of PPAR isoforms to PPAR $\alpha$ agonist GW7647 and PPAR $\delta$ agonist GW0742. Average data of three independent replicate FACTORIAL NR assays. C. Examining off-target activity mechanisms for PPAR ligands. The blue line graphs show NR activity fold-changes in response to Pio (at $5 \mu \mathrm{M})(\mathbf{a})$ or TBT $(0.1 \mu \mathrm{M})(\mathbf{b}),(\mathbf{c})$ vs. vehicle-treated cells. The red line graphs show NR activity profiles for the PPAR ligands in the presence of PPAR inhibitor T0070907 $(2 \mu \mathrm{M})(\mathbf{a})$, (b) or RXR inhibitor UVI3003 $(2 \mu \mathrm{M})(\mathbf{c})$ vs. vehicle-treated cells. Average profiles of three independent replicate FACTORIAL NR assays are shown. 


\begin{tabular}{|c|c|c|c|c|}
\hline Compound & NR & $\begin{array}{c}\text { EC50 by } \\
\text { Factorial NR }\end{array}$ & $\begin{array}{c}\text { EC50 range, } \\
\text { literature data }\end{array}$ & References \\
\hline 1,25-dihydroxyvitamin D3 & VDR & $1.2 \mathrm{nM}$ & $1.0-3.28 \mathrm{nM}$ & lä, 2005; Carballa, 2012 \\
\hline 4-Hydroxytamoxifen & $\mathrm{ER} \alpha$ & $1.0 \mathrm{nM}$ & $0.5-10.3 \mathrm{nM}$ & e, 2003; Renaud, 2003 \\
\hline 4-Hydroxytamoxifen & $E R \beta$ & $0.8 \mathrm{nM}$ & $0.5-32 \mathrm{nM}$ & d, 2003; Wallace, 2003 \\
\hline 4-Hydroxytamoxifen & $\mathrm{ERR} \gamma$ & $22 \mathrm{nM}$ & \begin{tabular}{l|l}
$10.9-2,000 \mathrm{nM}$ & Okad \\
\end{tabular} & 2008; Coward, 2001 \\
\hline Aldosterone & MR & $0.24 \mathrm{nM}$ & $0.08-1.0 \mathrm{nM}$ & Levy, 1999; Rogerson, 1999 \\
\hline Bexarotene & $\mathrm{RXR} \alpha$ & $4.9 \mathrm{nM}$ & $33-40 \mathrm{nM}$ & , 1994; Desphande, 2014 \\
\hline Bexarotene & $\mathrm{RXR} \beta$ & $2.9 \mathrm{nM}$ & $24 \mathrm{nM}$ & , 1994 \\
\hline Bexarotene & $\mathrm{RXR} \gamma$ & $3.1 \mathrm{nM}$ & $9-25 n M$ & 2015; Boehm, 1994 \\
\hline CDCA & FXR & $19.2 \mathrm{uM}$ & $8.3-45$ uM & n, 2008; Houck, 2004 \\
\hline Dexamethasone & GR & $1.9 \mathrm{nM}$ & $1-2.3 \mathrm{nM}$ & Levy, 1999; Rupprecht, 1993 \\
\hline DHT & $\mathrm{AR}$ & $0.81 \mathrm{nM}$ & $0.7-8.4 \mathrm{nM}$ & 2008; Schlienger, 2009 \\
\hline $17 \beta$ estradiol & $\mathrm{ER} \alpha$ & $0.7 \mathrm{nM}$ & $0.02-3.0 \mathrm{nM}$ & fer, 2002; Gaido, 2000 \\
\hline $17 \beta$ estradiol & $\mathrm{ER} \beta$ & $1.1 \mathrm{nM}$ & $0.1-7.0 \mathrm{nM}$ & er, 2002; Gaido, 2000 \\
\hline Fexaramine & FXR & $530 \mathrm{nM}$ & $255 \mathrm{nM}$ & s, 2003 \\
\hline GW0742 & PPAR $\alpha$ & $0.9 \mathrm{uM}$ & $1.1-1.63$ uM & man, 2003; Nandhikonda, 2013 \\
\hline GW0742 & PPAR $\gamma$ & $2.8 \mathrm{uM}$ & $2.0-2.8 \mathrm{uM}$ & man, 2003; Nandhikonda, 2013 \\
\hline GW0742 & PPAR $\delta$ & $2.2 \mathrm{nM}$ & $1.0-3.7 \mathrm{nM}$ & man, 2003; Nandhikonda, 2013 \\
\hline GW4064 & FXR & $88 \mathrm{nM}$ & $70-90 \mathrm{nM}$ & 2019; Goodwin, 2000 \\
\hline GW7647 & PPAR $\alpha$ & $3.3 \mathrm{nM}$ & $6.0-6.0 \mathrm{nM}$ & , 2001; Seimandi, 2005 \\
\hline GW7647 & PPAR $\gamma$ & $376 \mathrm{nM}$ & $350-1,100 \mathrm{nM}$ & ndi, 2005; Brown, 2001 \\
\hline GW7647 & PPAR $\delta$ & $1.26 \mathrm{uM}$ & $0.94-6.0 \mathrm{uM}$ & ndi, 2005; Brown, 2001 \\
\hline Progesterone & PR & $2.9 \mathrm{nM}$ & $2.2-2.9 \mathrm{nM}$ & n, 2008; Tegley, 1998 \\
\hline Rifampicin & PXR & $0.73 \mathrm{uM}$ & $0.72-0.80 u \mathrm{M}$ & e, 2006; Lehmann, 1998 \\
\hline Rosiglitazone & PPAR $\gamma$ & $49 \mathrm{nM}$ & $18-220 \mathrm{nM}$ & ndi, 2005; Mahindroo, 2006 \\
\hline T0901317 & $\mathrm{LXR} \alpha$ & $24 \mathrm{nM}$ & $20-50 \mathrm{nM}$ & 2000; Li, 2017 \\
\hline T0901317 & LXR $\beta$ & $40 \mathrm{nM}$ & $20-60 \mathrm{nM}$ & , 2000; Li, 2017 \\
\hline T3 & $\mathrm{THR} \alpha$ & $0.67 \mathrm{nM}$ & $1.2-2.4 \mathrm{nM}$ & nn, 2009; Cory, 2006 \\
\hline $\mathrm{T3}$ & THR $\beta$ & $0.37 \mathrm{nM}$ & $1.6-2.4 \mathrm{nM}$ & nn, 2009; Cory, 2006 \\
\hline XCT790 & $\mathrm{ERR} \alpha$ & $165 \mathrm{nM}$ & $370-541 \mathrm{nM}$ & 2004; Willy, 2004 \\
\hline Reference & DOI: & & Reference & DOI: \\
\hline Boehm, 1994 & 10.1021/jm000 & $\mathrm{a} 014$ & Merk, 2019 & $10.1038 / \mathrm{s} 41467-019-10853-2$ \\
\hline Brown, 2001 & $10.1016 / \mathrm{s} 0960$ & $94 \times(01) 00188-3$ & Nandhikonda, 2013 & $10.1021 /$ bi400321p \\
\hline Busch, 2004 & 10.1021/jm049 & & Okada, 2008 & 10.1289/ehp.10587 \\
\hline Carballa, 2012 & 10.1021/jm300 & 272 & Pedram, 2008 & 10.1021/jm8004256 \\
\hline Cory, 2006 & $10.1021 / \mathrm{cb} 600$ & & Peräkylä, 2005 & 10.1210/me.2004-0417 \\
\hline Coward, 2001 & 10.1073/pnas. & 1244398 & Renaud, 2003 & 10.1021/jm030086h \\
\hline Desphande, 2014 & 10.1016/j.bmc. & 13.11 .039 & Rogerson, 1999 & 10.1074/jbc.274.51.36305 \\
\hline Downes, 2003 & $10.1016 / \mathrm{s} 1097$ & $765(03) 00104-7$ & Rupprecht, 1993 & 10.1016/0922-4106(93)90072-h \\
\hline Gaido, 2000 & $10.1124 / \mathrm{mol} .5$ & .852 & Schlienger, 2009 & 10.1021/jm901149c \\
\hline Giner, 2015 & 10.1096/fj.14-2 & 9804 & Schopfer, 2002 & 10.1021/jm015577I \\
\hline Goodwin, 2000 & $10.1016 / \mathrm{s} 1097$ & $765(00) 00051-4$ & Schultz, 2000 & $10.1101 / \mathrm{gad} .850400$ \\
\hline Hellal-Levy, 1999 & $10.1016 / s 0014$ & $793(99) 01667-1$ & Seimandi, 2005 & 10.1016/j.ab.2005.06.010 \\
\hline Hofmann, 2009 & 10.1093/toxsci & p086 & Soisson, 2008 & 10.1073/pnas.0710981105 \\
\hline Houck, 2004 & 10.1016/j.ymgr & .2004 .07 .007 & Sznaidman, 2003 & $10.1016 / \mathrm{s} 0960-894 \times(03) 00207-5$ \\
\hline Lehmann, 1998 & 10.1172/JCI37 & & Tegley, 1998 & 10.1021/jm980366a \\
\hline Lemaire, 2006 & 10.1093/toxsci & fj173 & Wallace, 2003 & $10.1016 / \mathrm{s} 0960-894 \times(03) 00306-8$ \\
\hline Li, 2017 & 10.1124/mol.1 & .105213 & Willy, 2004 & 10.1073/pnas.0401420101 \\
\hline Mahindroo, 2006 & 10.1021/jm051 & 373 & Zhou, 2008 & 10.1038/bjp.2008.107 \\
\hline
\end{tabular}


Table 1. The inferred EC50 values by the FACTORIAL NR assay vs. the literature data. The table shows the inferred EC50 values by the FACTORIAL NR assay vs. the literature data. The EC50 estimates by the FACTORIAL NR are average values of at least three independent replicate assays. 
GAL4-NR reporter module

A

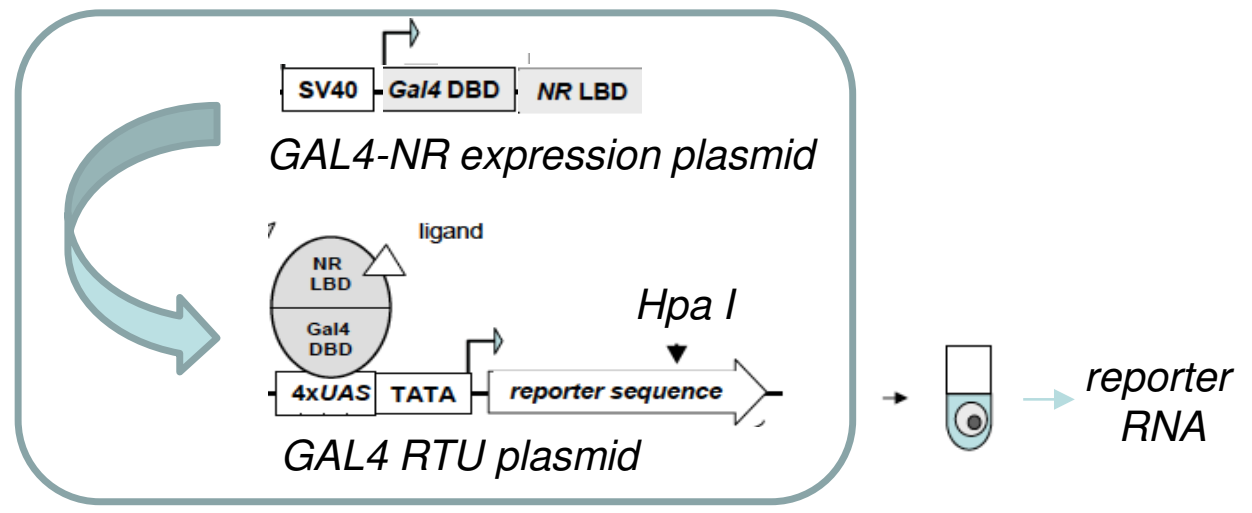

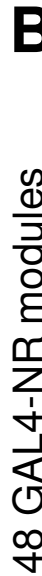

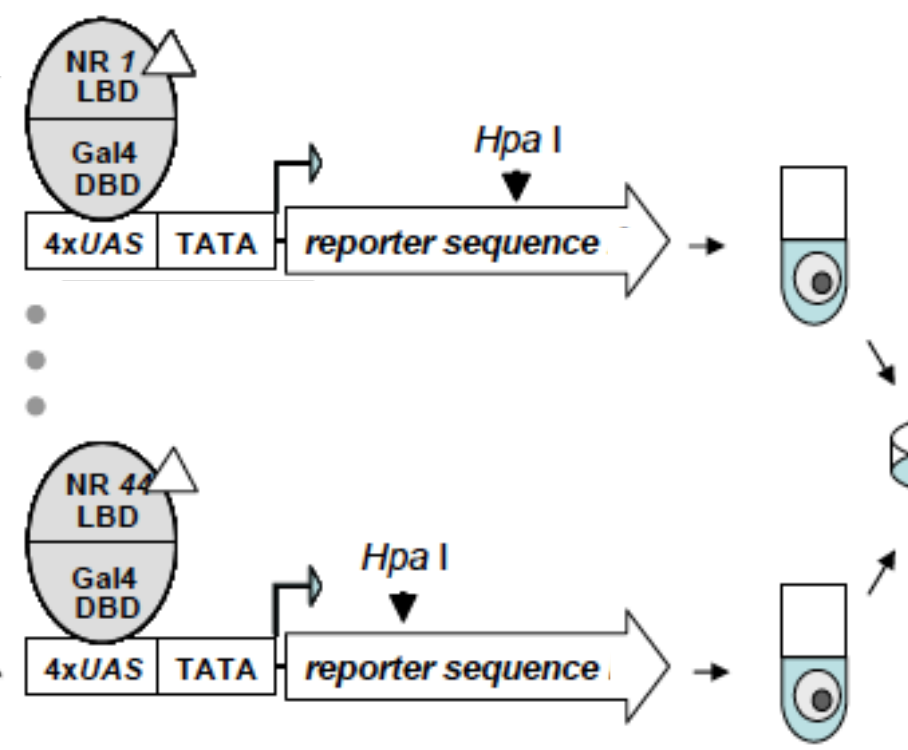

CE fluorescence

NR48

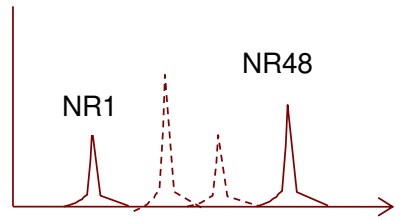

Evaluated

compound
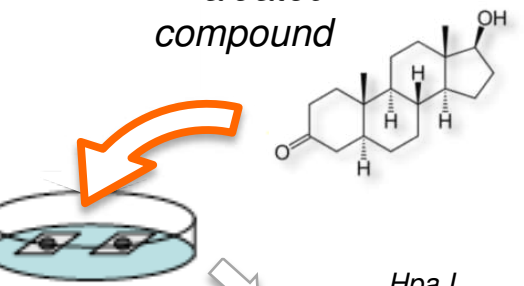

RNA

Hpa I

$\nabla$

7

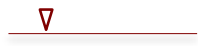

cDNA

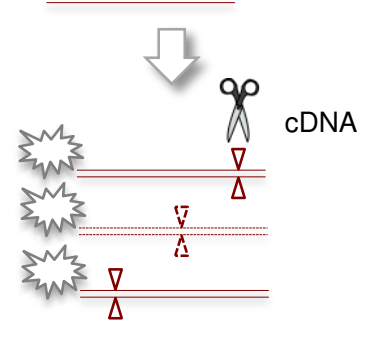

Medvedev et al., Fig. 1 


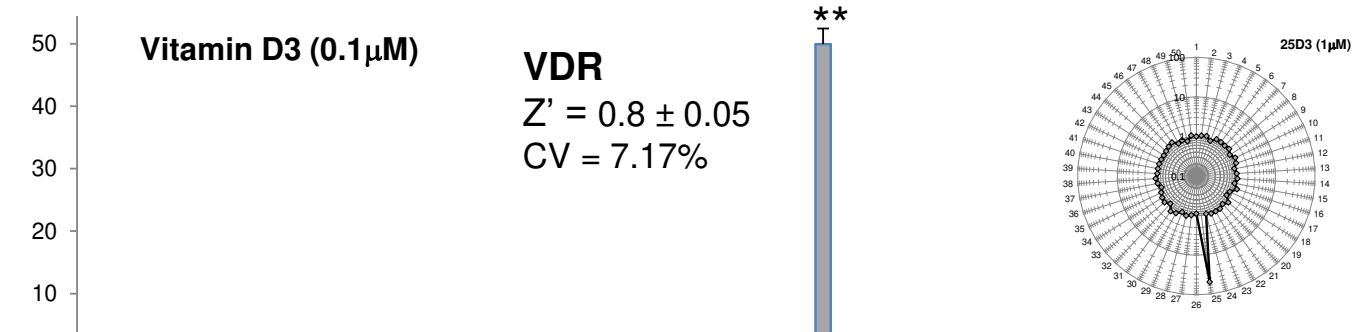

$0+\frac{1}{1+n}$

1234567891011121314151617181920212223242526272829303132333435363738394041424344454647484950

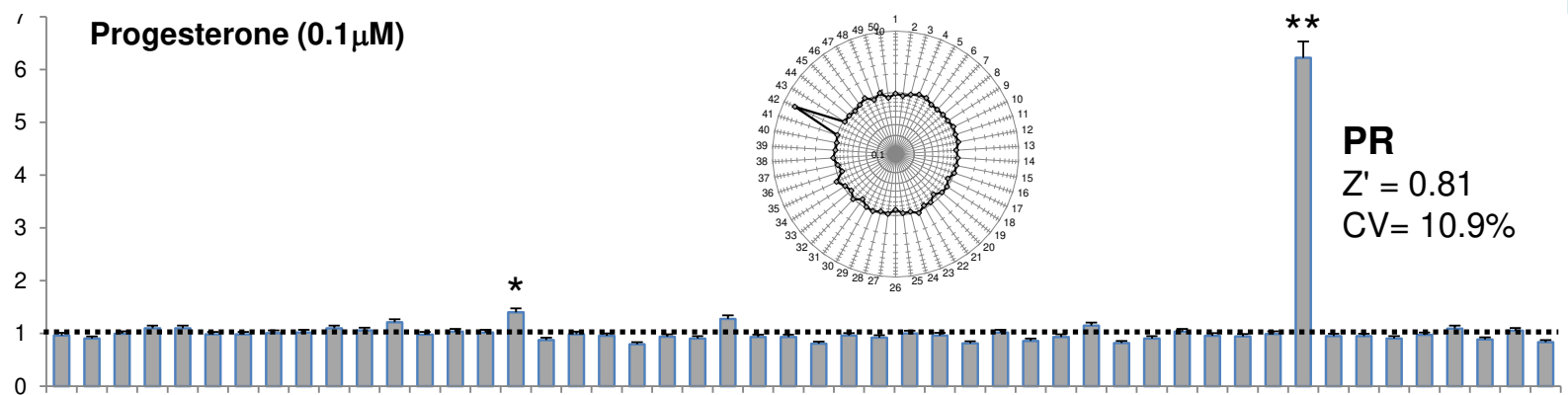

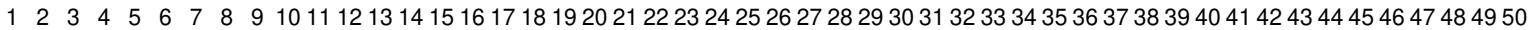

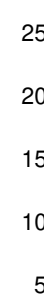

25

0

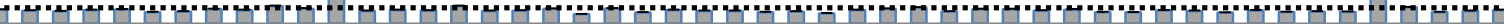

$123 \quad 3 \quad 4 \quad 5 \quad 6 \quad 7 \quad 8 \quad 91011121314151617181920212223242526272829303132333435363738394041424344454647484950$

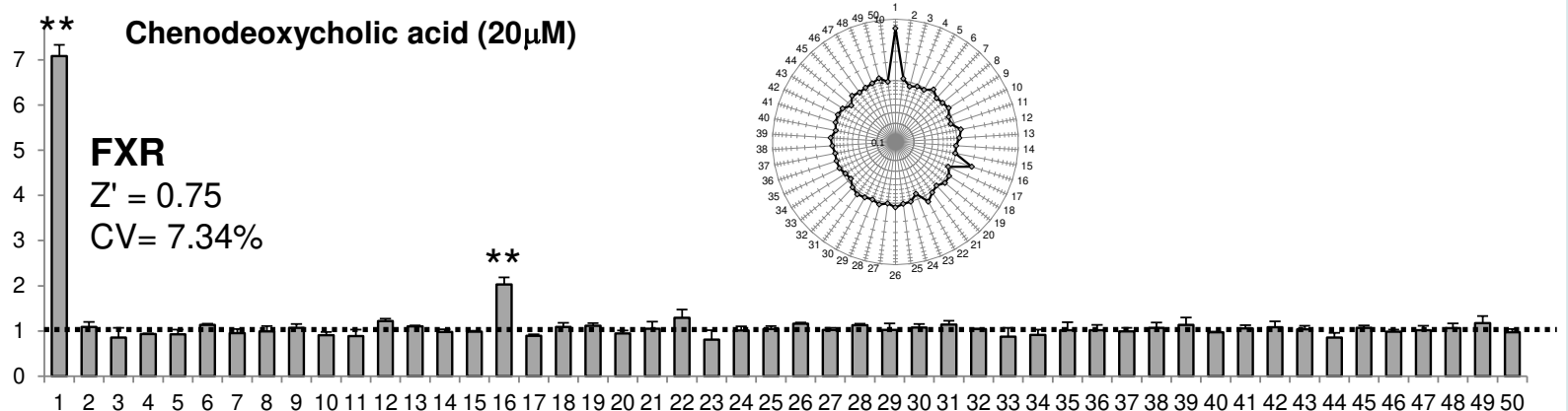

Estradiol $(0.1 \mu \mathrm{M})$

ER $\alpha$

$Z^{\prime}=0.77$

$\mathrm{CV}=6.35 \%$

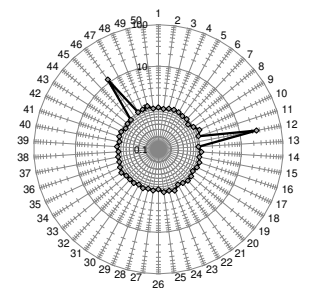

ER $\beta$

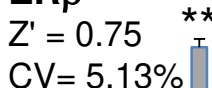

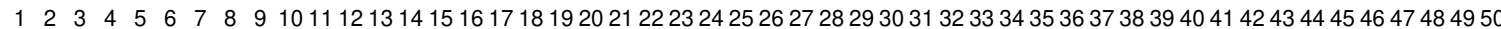

Triiodothyronine $(0.1 \mu \mathrm{M})$

THR $\alpha$

$Z^{\prime}=0.78$

$\mathrm{CV}=6.70 \%$

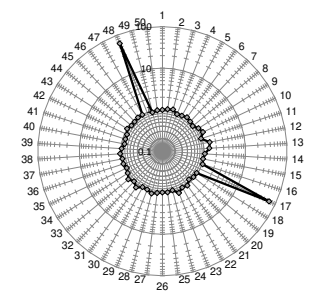

THR $\beta$

$Z^{\prime}=0.75$

$\mathrm{CV}=7.48 \%$

\section{**}

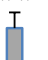

1 
C

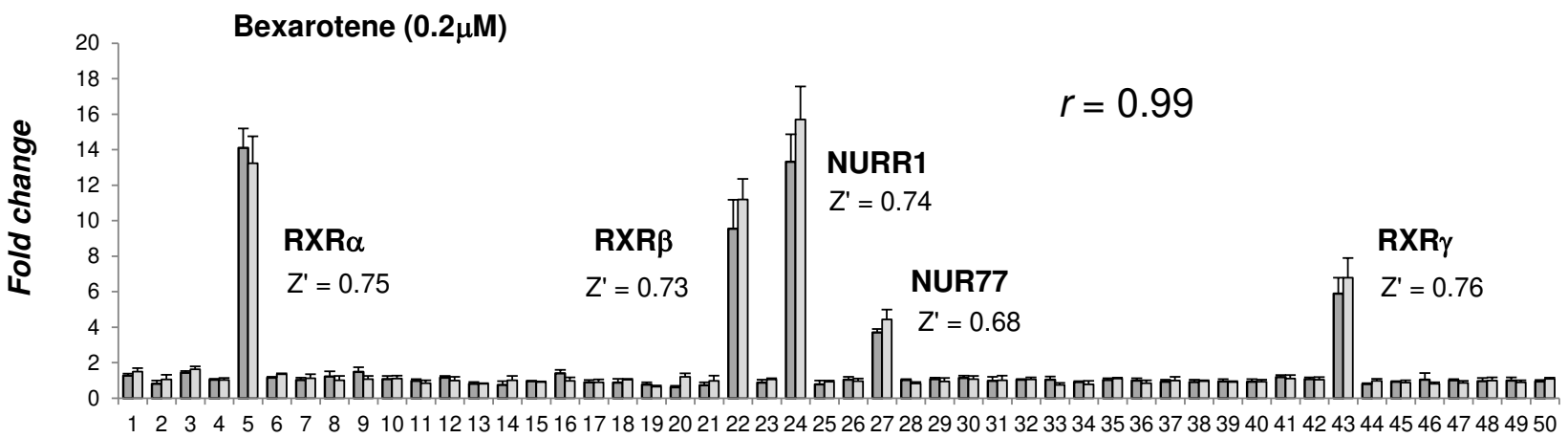

Fig. $2 \mathrm{C}$ 
VDR,

fold-induction

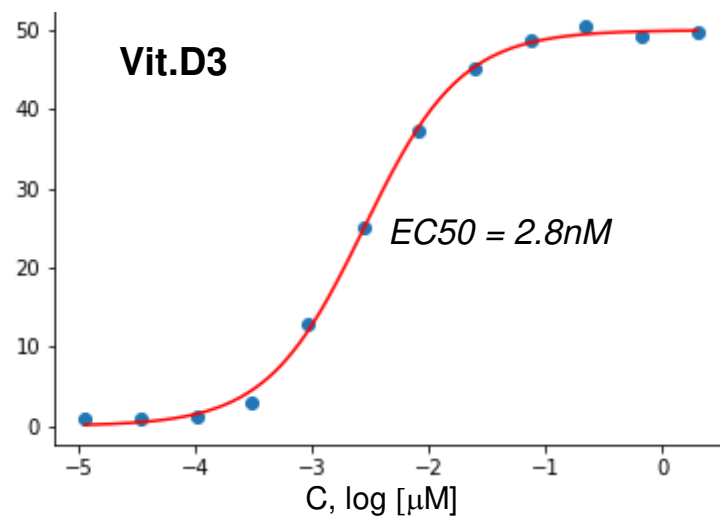

ER $\alpha$,

fold-induction

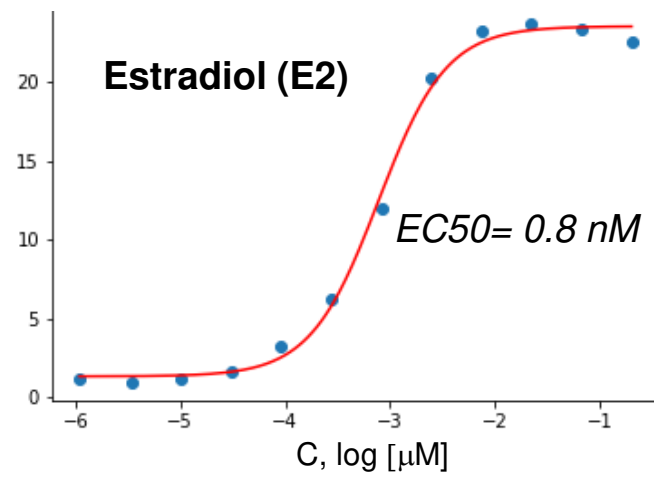

TR $\alpha$,

fold-induction

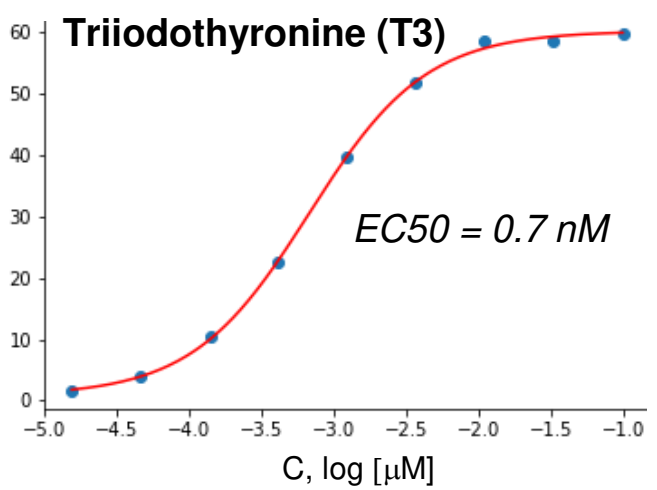

FXR,

fold-induction

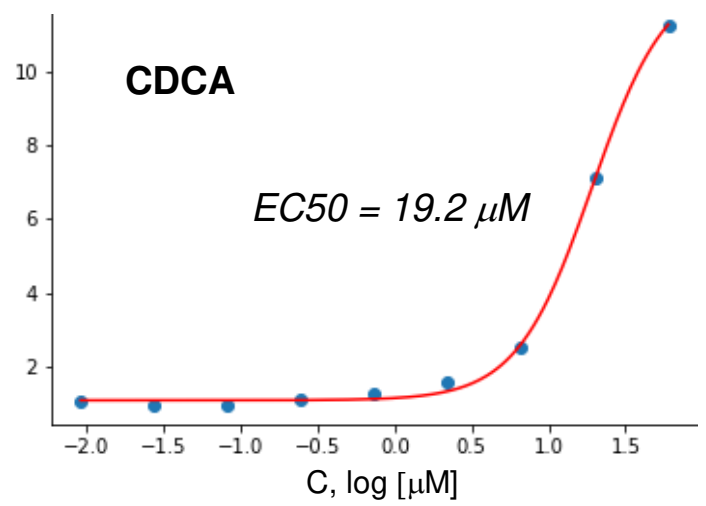

PR,

fold-induction

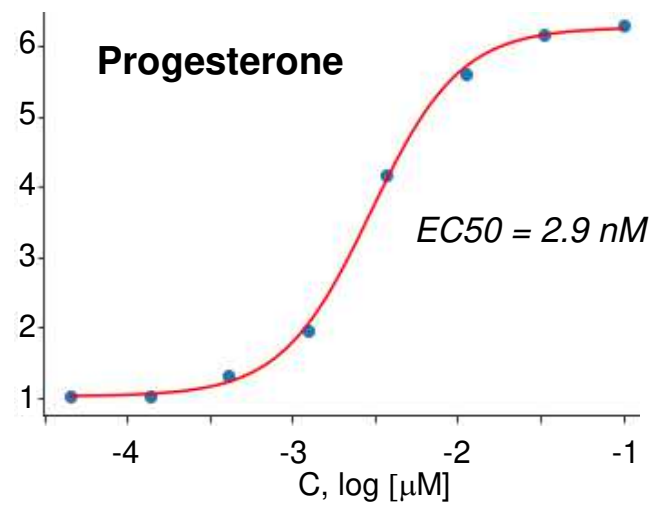

ER $\beta$,

fold-induction

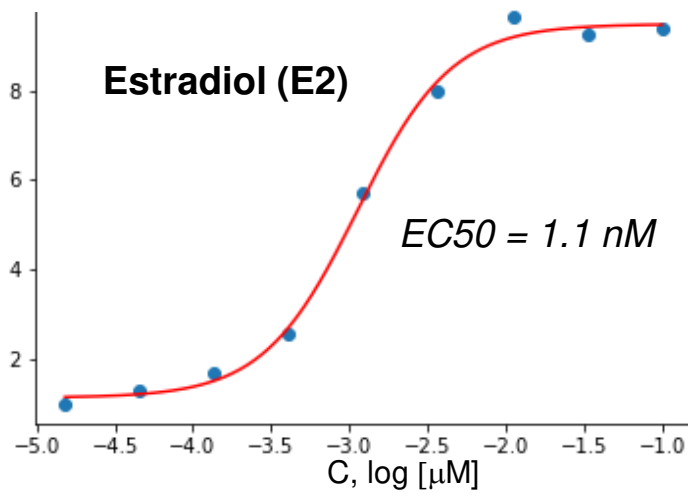

TR $\beta$,

fold-induction

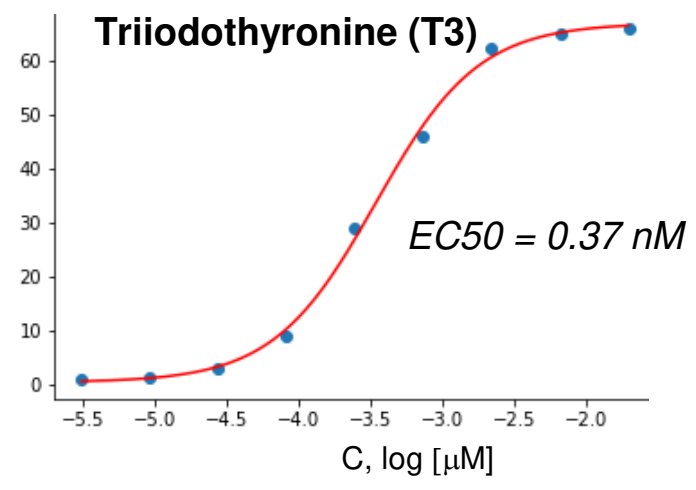


GR,

fold-induction

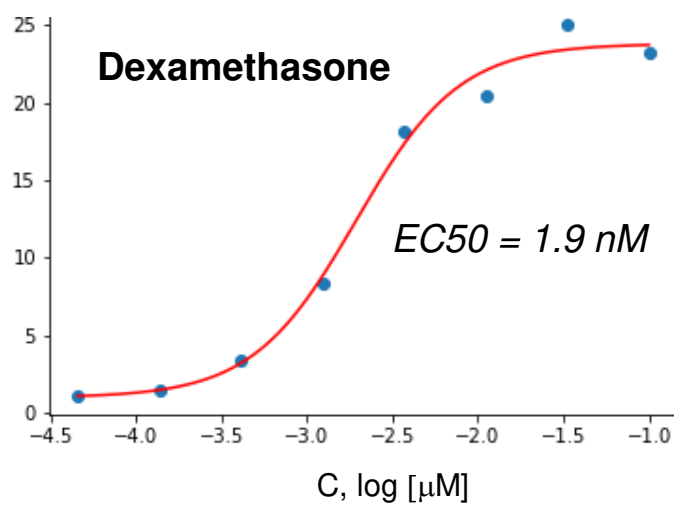

LXR,

fold-induction

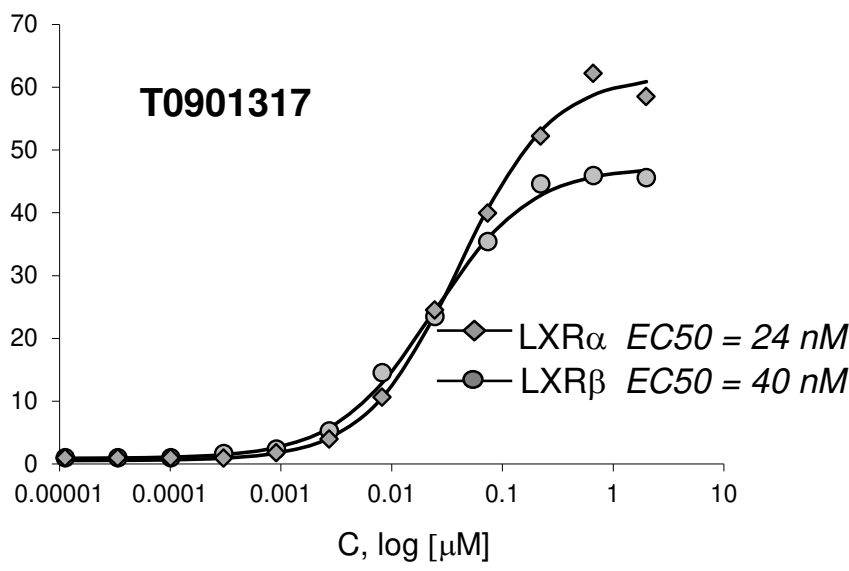

PPAR $\gamma$,

fold-induction

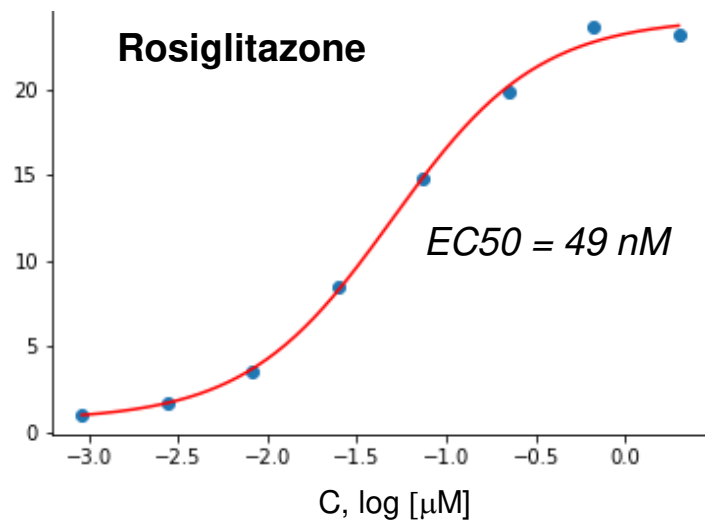

AR,

fold-induction

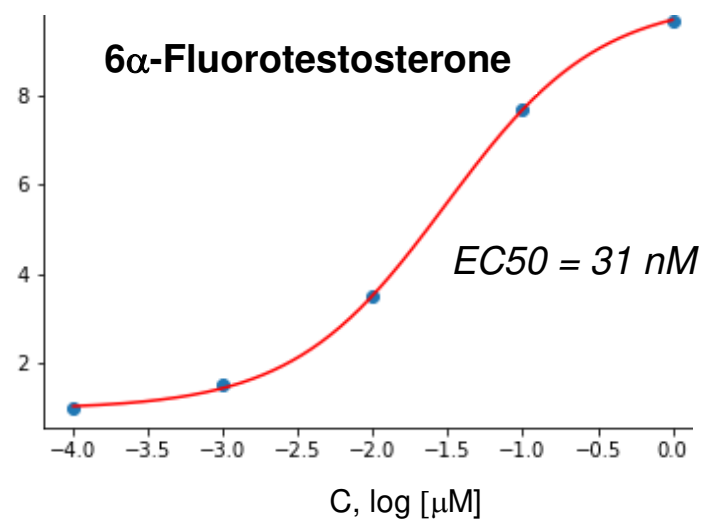


A

ROR $\gamma$ antagonist

GSK805 $(0.07 \mu \mathrm{M})$
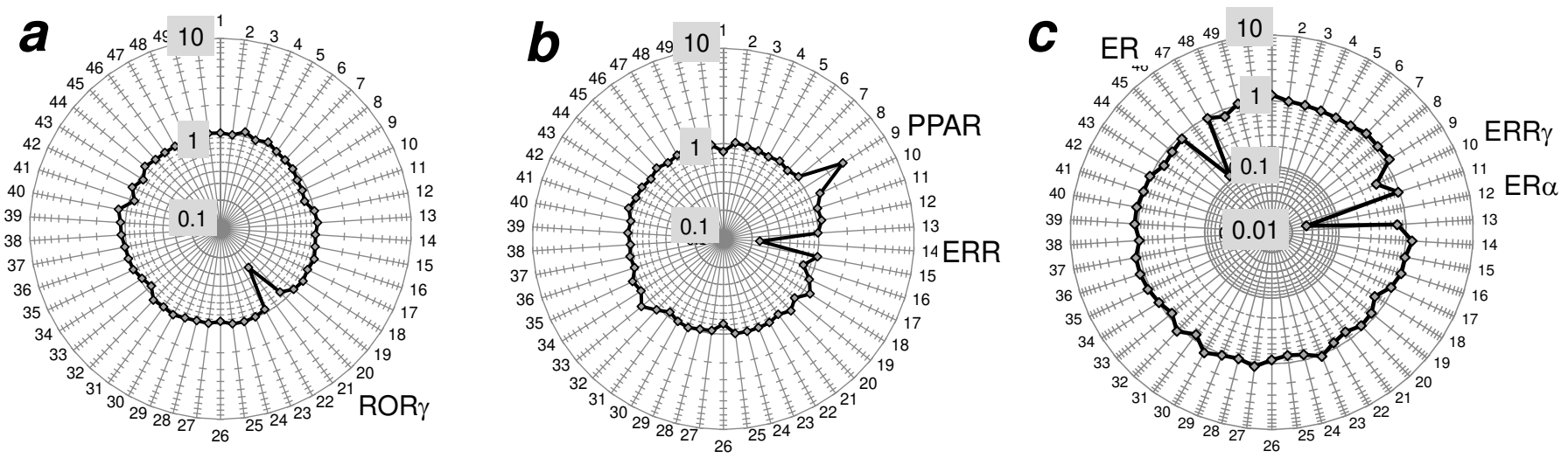

ER antagonist

4-HT $(4 \mu \mathrm{M}) / \mathrm{E} 2[0.4 \mu \mathrm{M}]$ a ROR $\boldsymbol{\gamma}, \%$ of max. activity

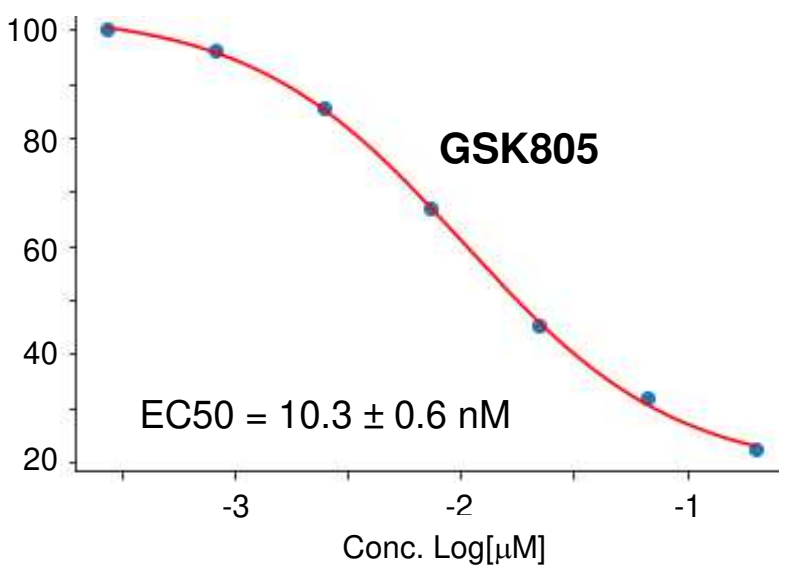

C ER $\alpha$ fold induction vs. that in E2-stimulated cells

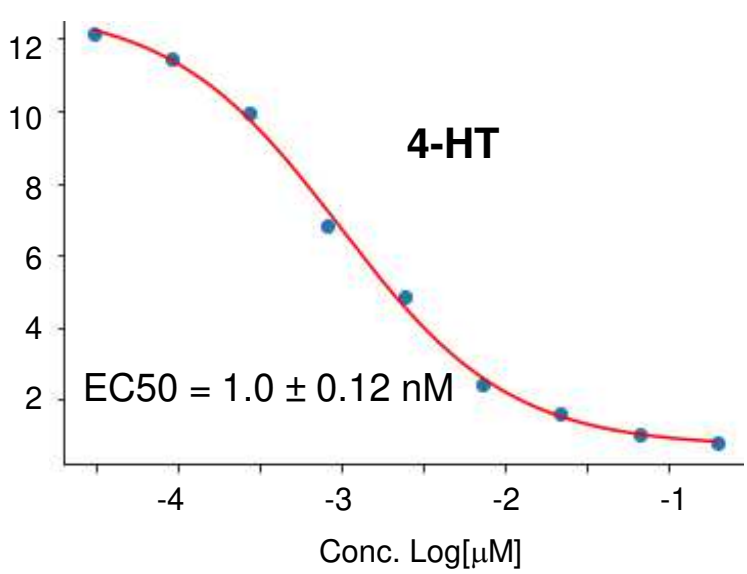

b ERR $\boldsymbol{\alpha}, \%$ of max. activity

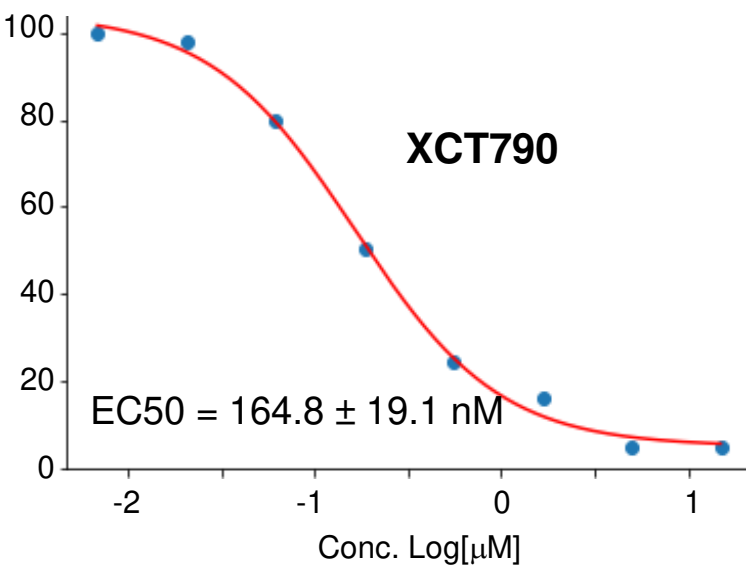

ER $\beta$ fold induction vs. that in E2-stimulated cells

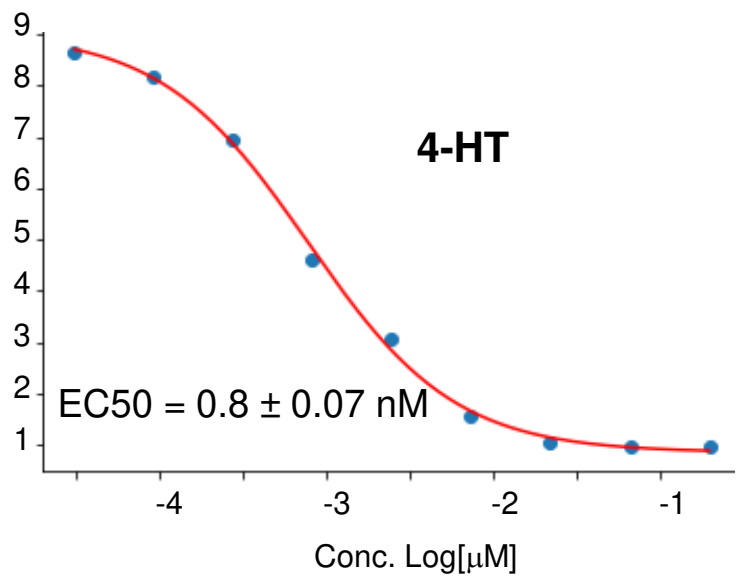


PR, \% of max. induction

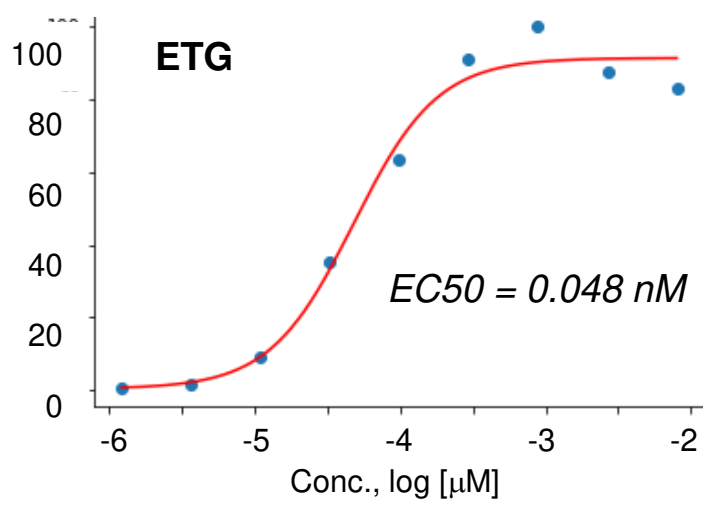

PR. \% of max. induction

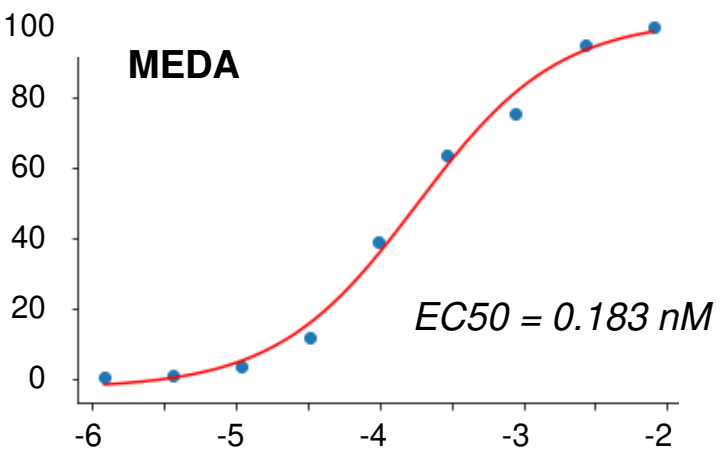

C
PR, \% of max. induction

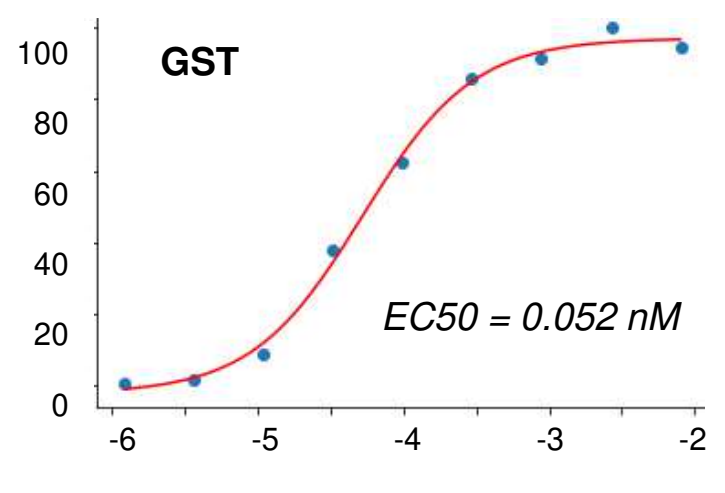

Progestin EC50 (PR)

$\begin{array}{ll}\text { ETG } & 0.048 \mathrm{nM} \\ \text { GST } & 0.052 \mathrm{nM} \\ \text { MEDA } & 0.183 \mathrm{nM} \\ \text { NMG } & 0.491 \mathrm{nM} \\ \text { LVG } & 0.153 \mathrm{nM} \\ \text { ETD } & 0.949 \mathrm{nM}\end{array}$
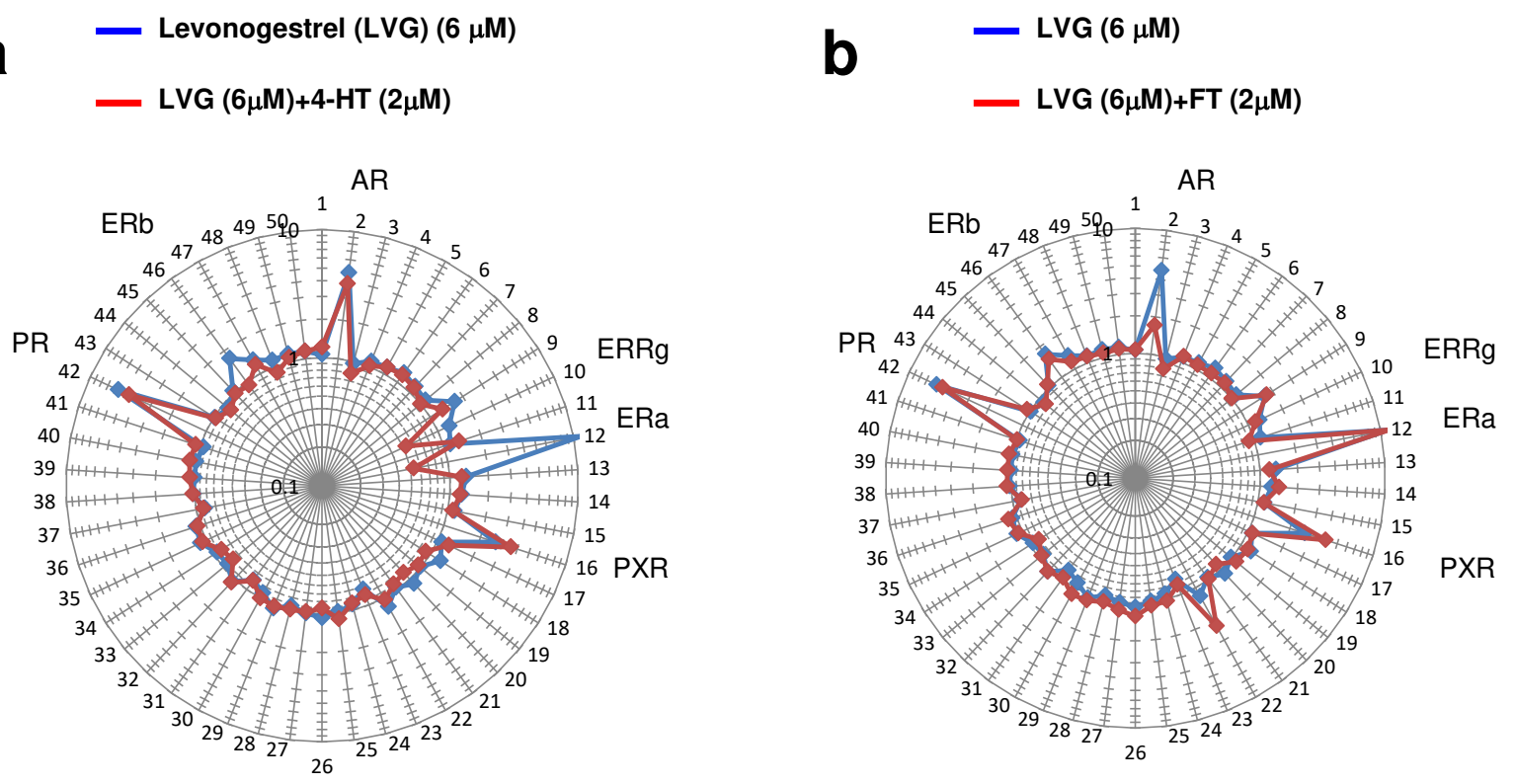
Figures

\section{GAL4-NR reporter module}
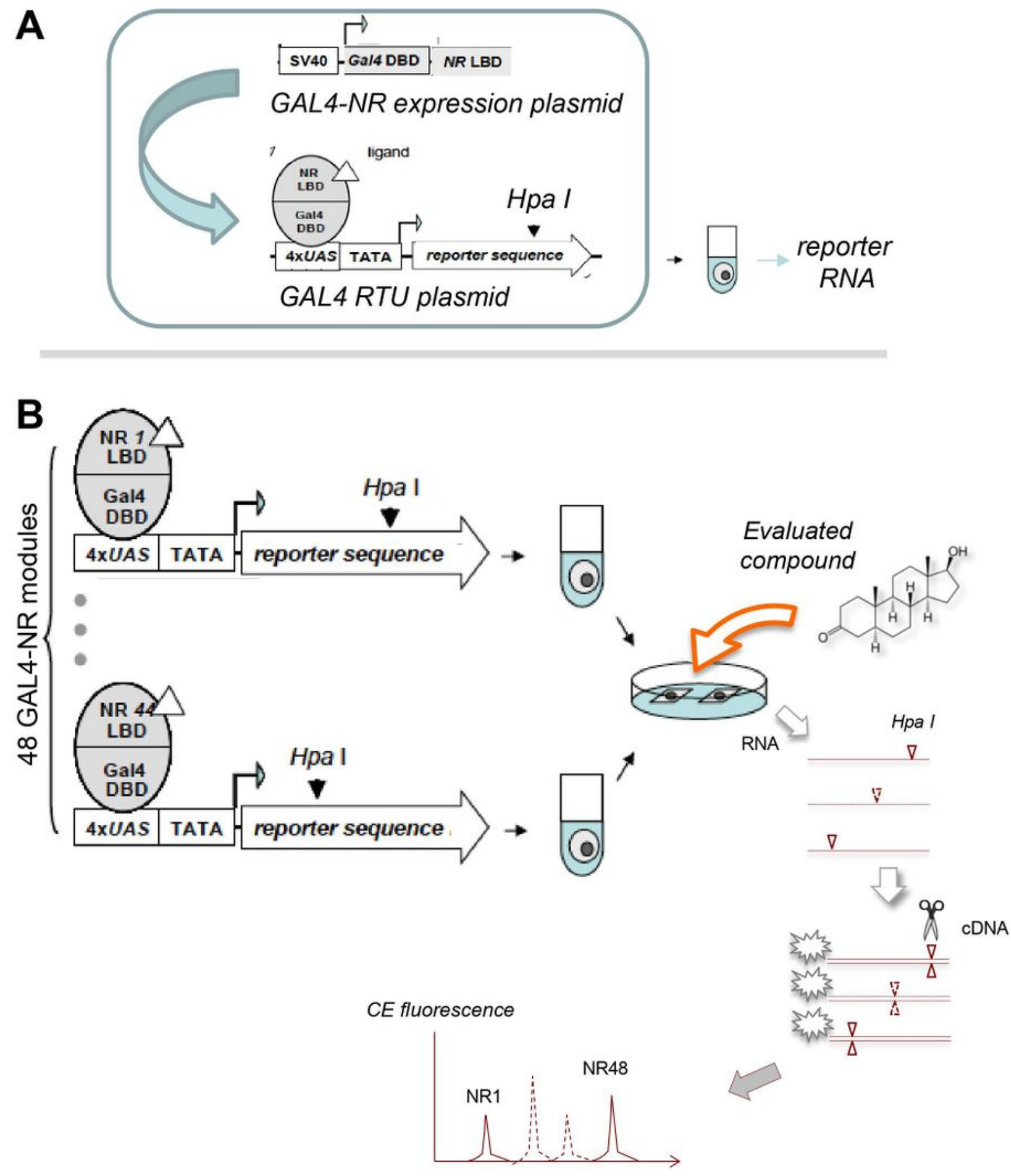

Figure 1

Please see the Manuscript PDF file for the complete figure caption 


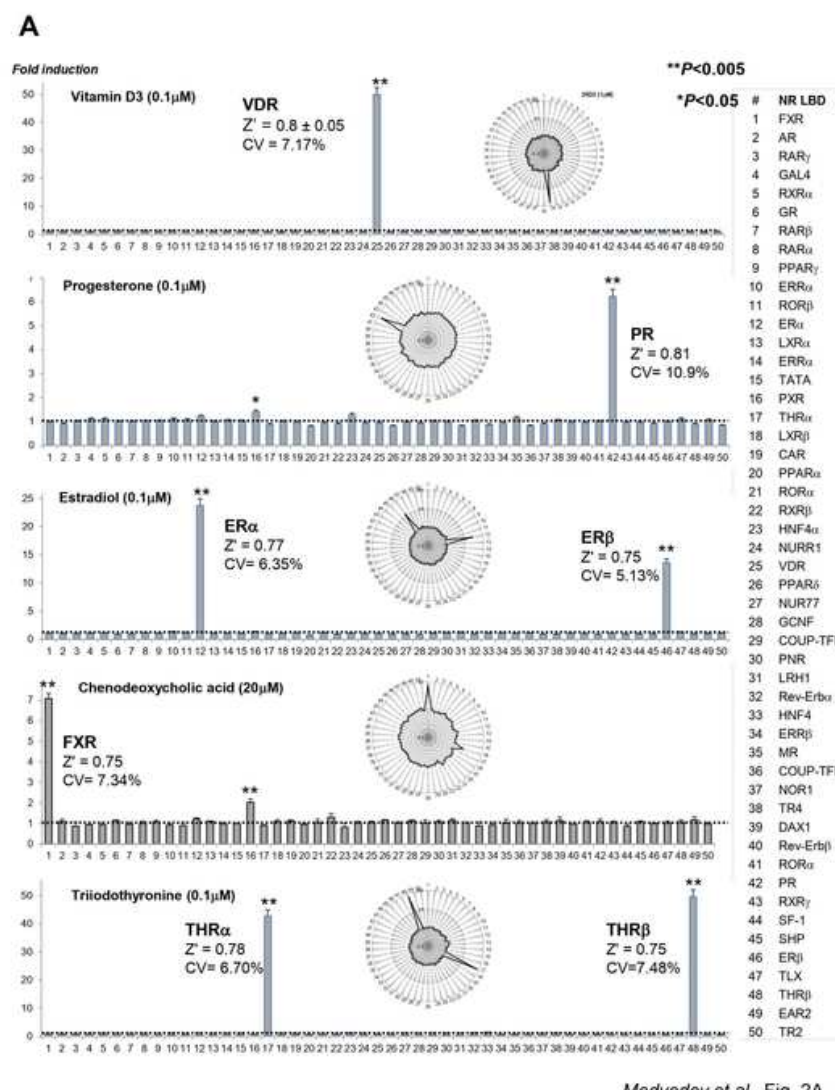

\section{B}
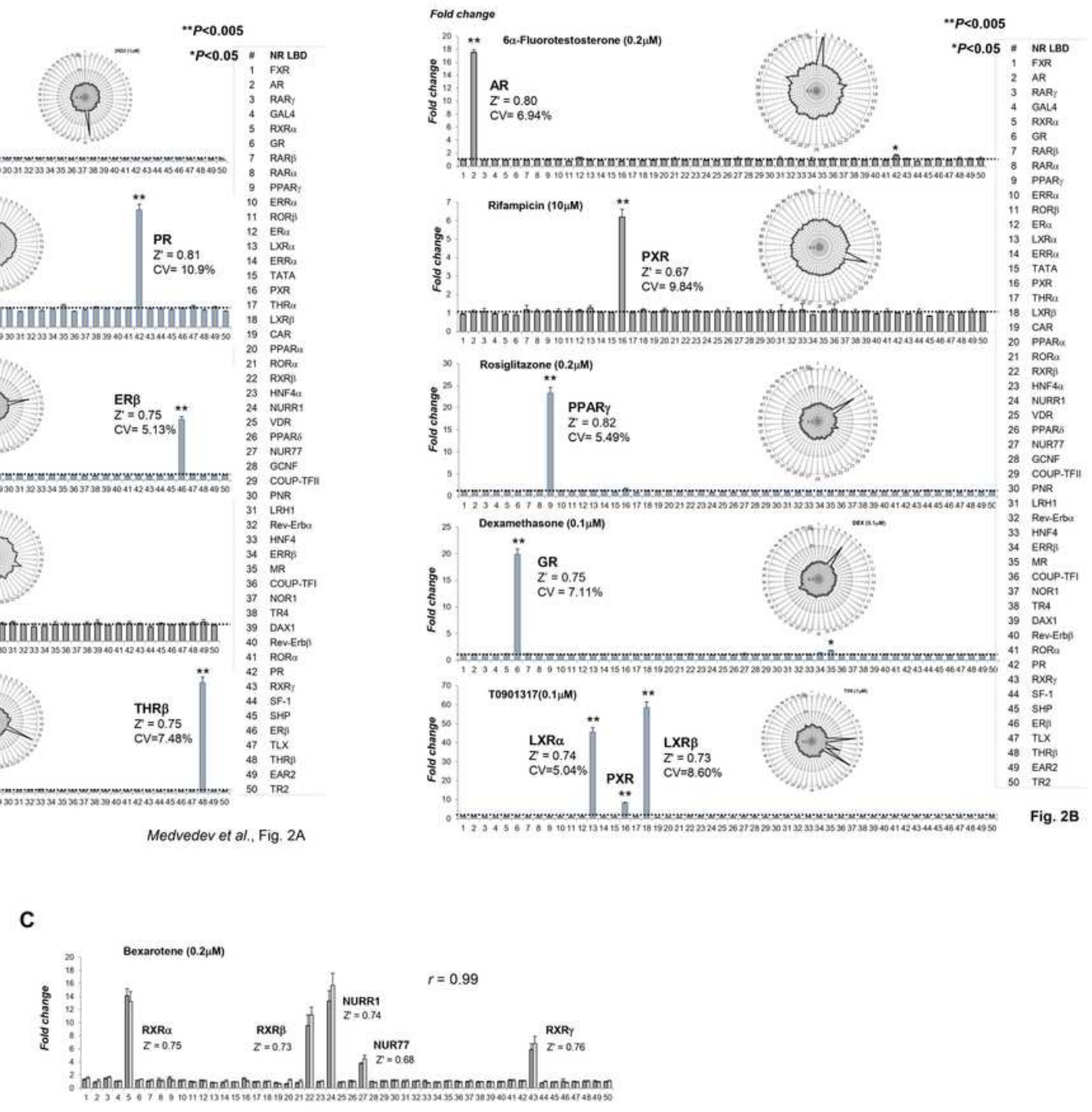

Figure 2

Please see the Manuscript PDF file for the complete figure caption 
VDR,

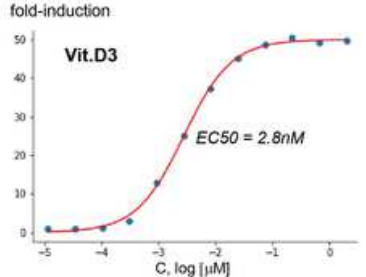

ERa,

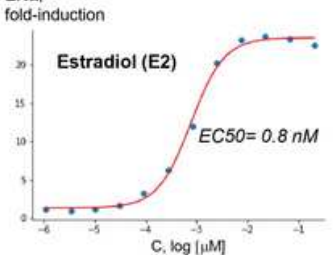

TRa,

fold-induction

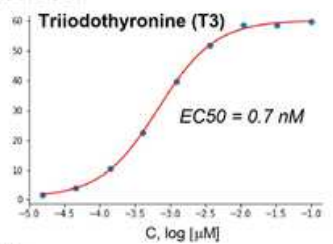

FXR

fold-induction

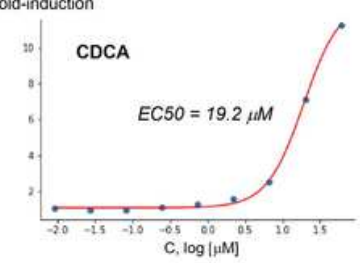

PR,

fold-induction

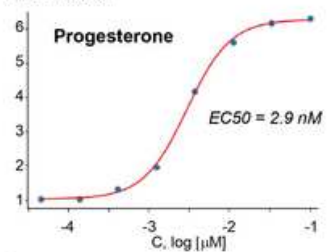

ERß,

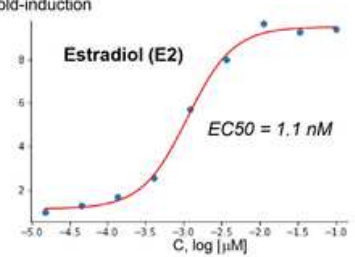

TR $\beta$.

TR $\beta$,
fold-induction

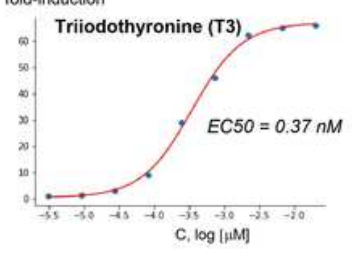

GR.

fold-induction

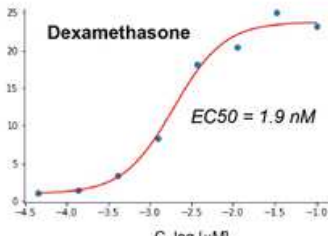

C, $\log [\mu \mathrm{M}]$

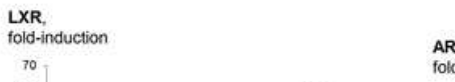

${ }_{60}^{70}-\quad$ T0901317

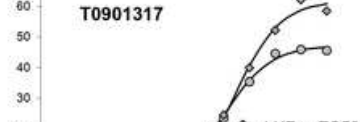

${ }_{20}^{30} \quad 1-L X R a E C 50=24 \mathrm{nM}$

10.

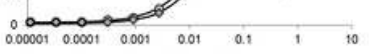

C, $\log [\mu \mathrm{M}]$
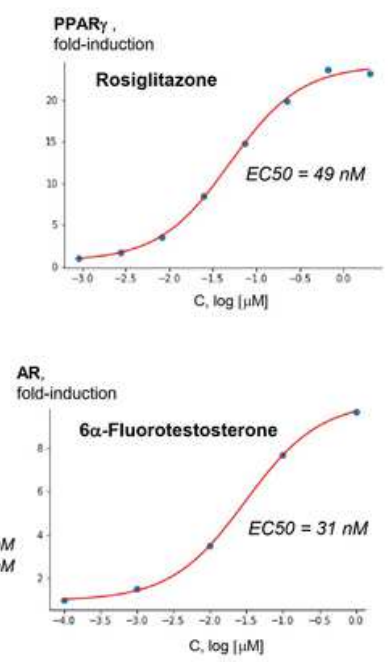

Fig. 3 (Cont.)

Figure 3

Please see the Manuscript PDF file for the complete figure caption 
A $\quad \begin{aligned} & \text { ROR } \gamma \text { antagonist } \\ & \text { GSK805 }(0.07 \mu \mathrm{M})\end{aligned}$

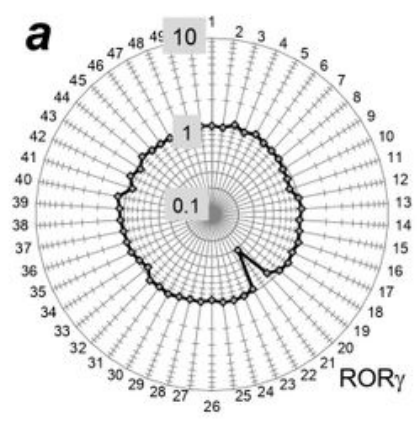

B

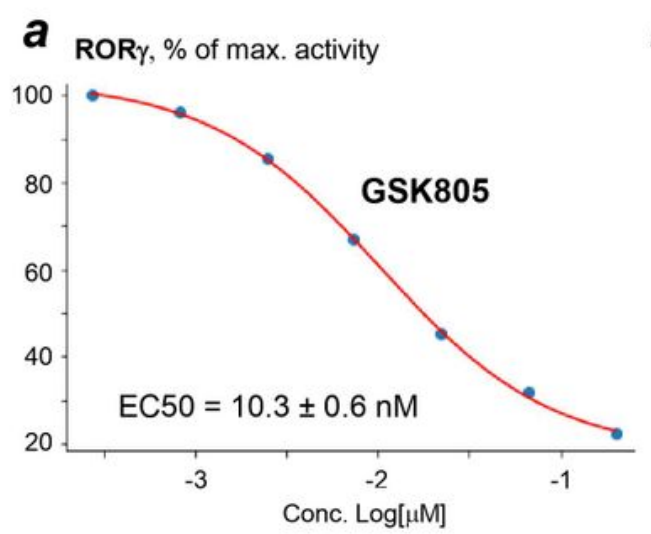

C ER $\alpha$ fold induction vs. that in E2-stimulated cells

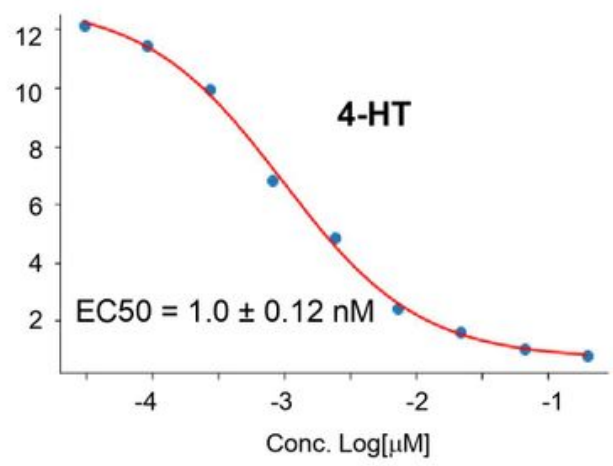

ER antagonist

4-HT $(4 \mu \mathrm{M}) / \mathrm{E} 2[0.4 \mu \mathrm{M}]$

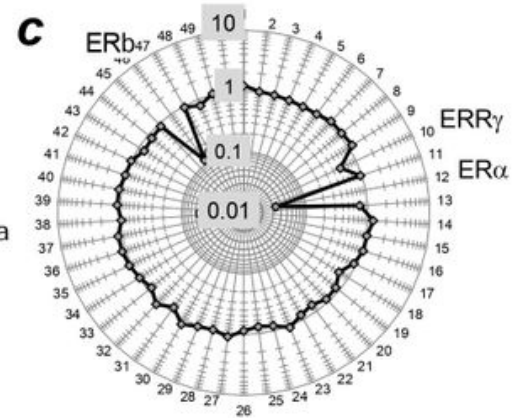

b ERR $\alpha$, \% of max. activity

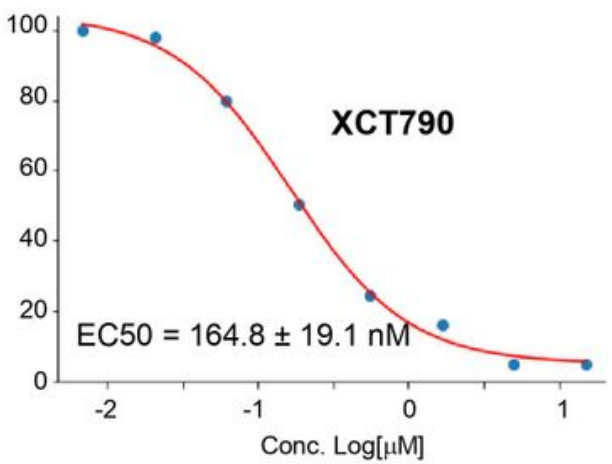

ER $\beta$ fold induction vs. that in E2-stimulated cells

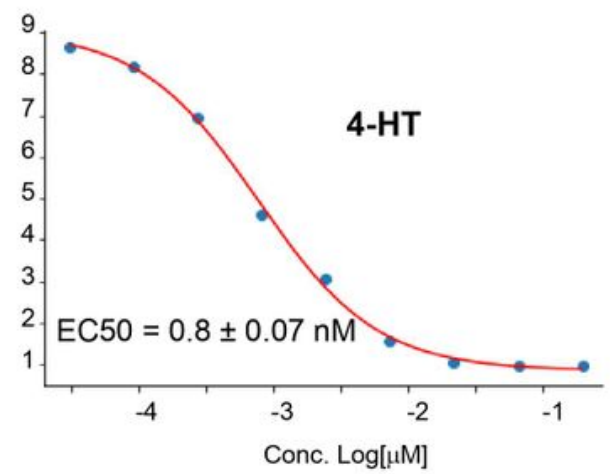

Medvedev et al., Fig. 4

\section{Figure 4}

Please see the Manuscript PDF file for the complete figure caption 


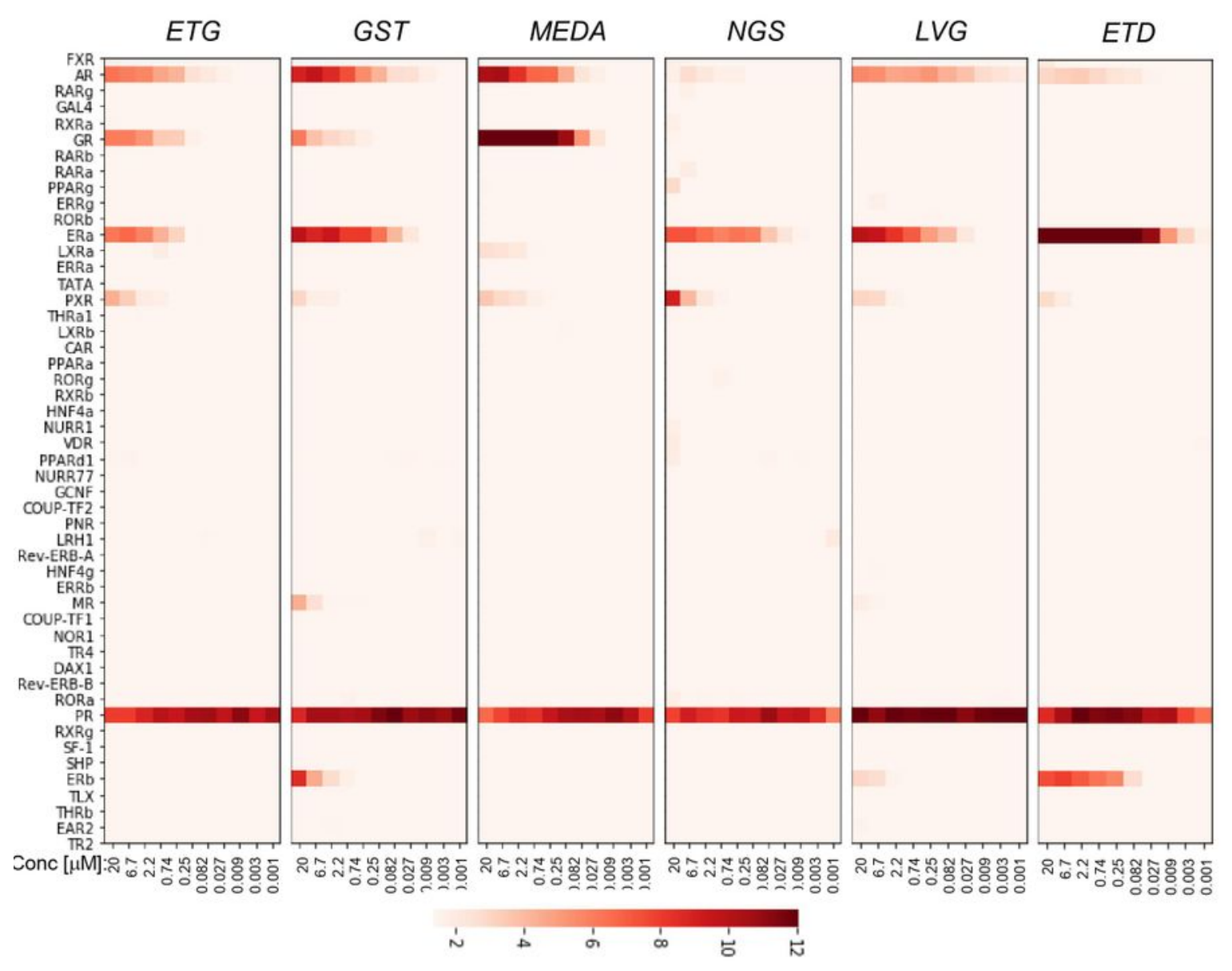

Medvedev et al., Fig. 5

Figure 5

Please see the Manuscript PDF file for the complete figure caption 

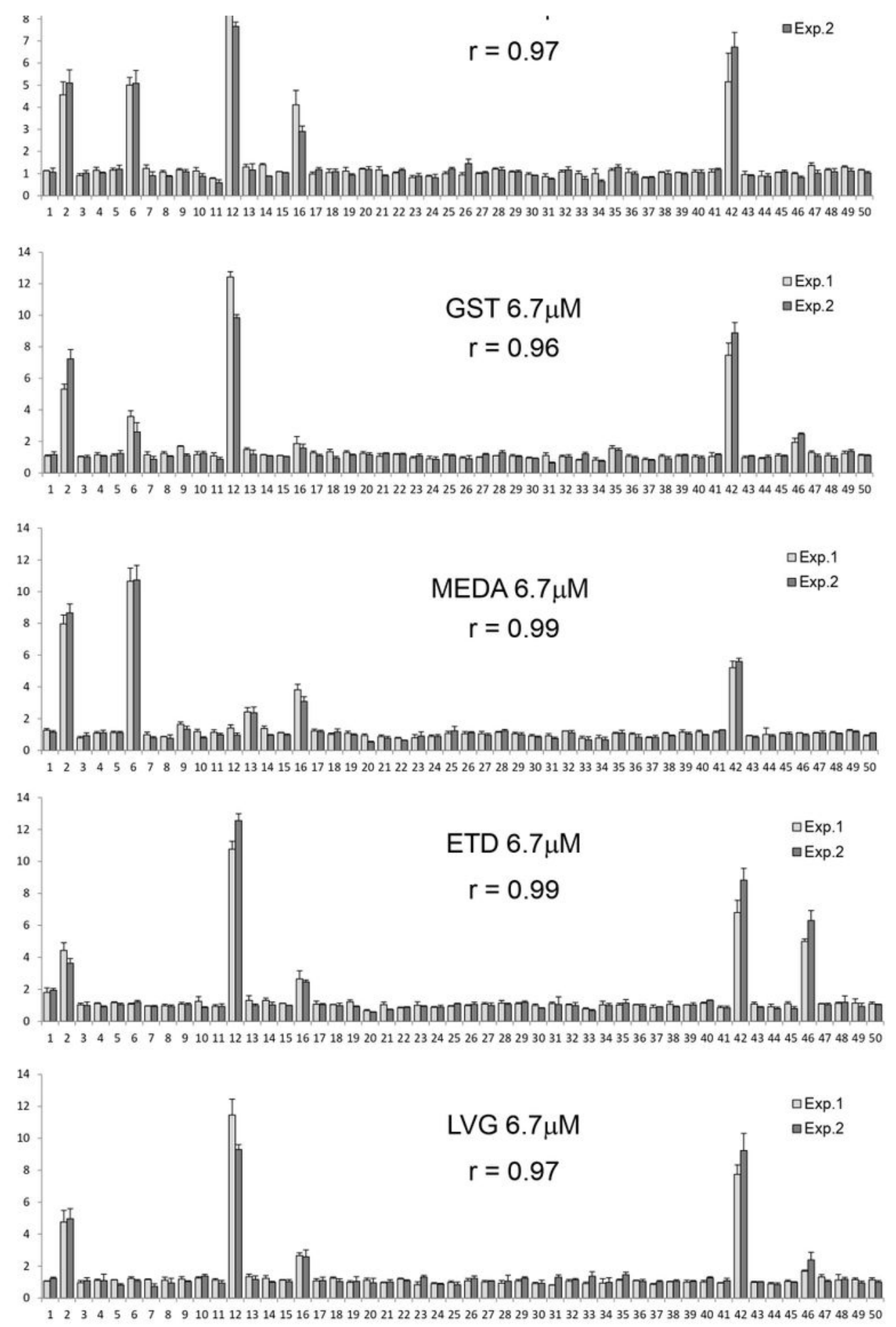

Medvedev et al., Fig. 6

Figure 6

Please see the Manuscript PDF file for the complete figure caption 
A
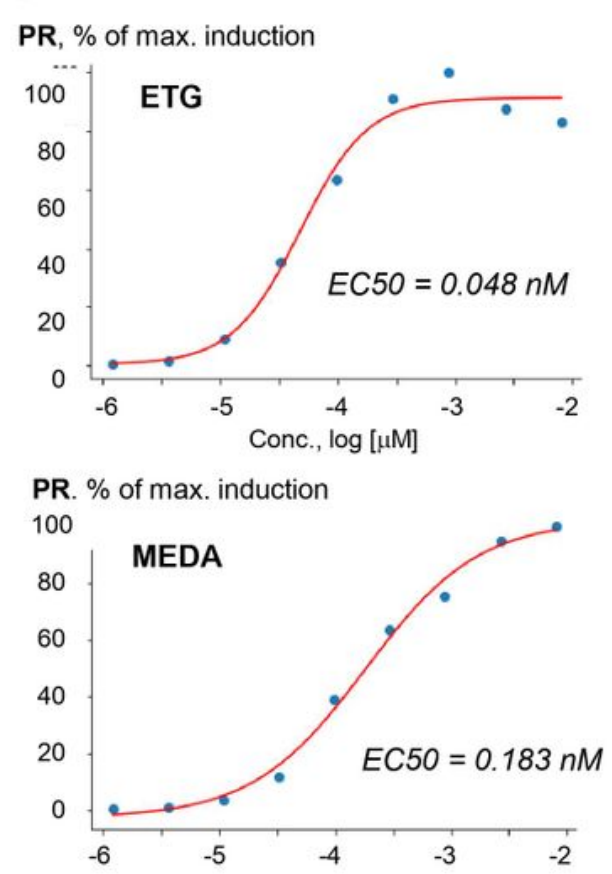

C

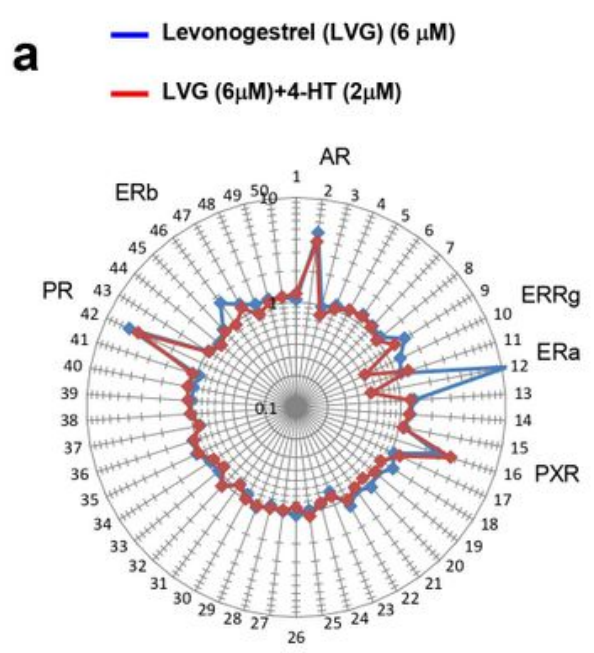

PR, \% of max. induction

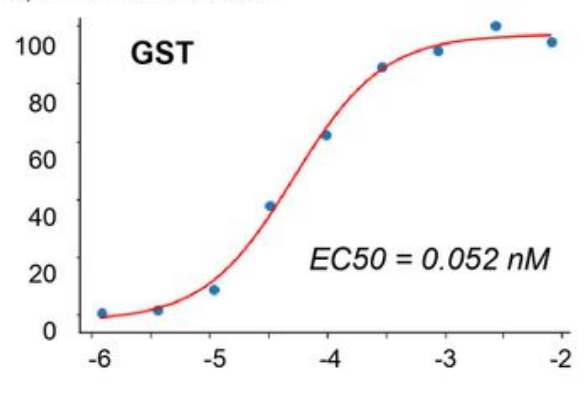

b $\quad-\operatorname{LVg}(6 \mu \mathrm{M})$
$-\operatorname{LVG}(6 \mu \mathrm{M})+\mathrm{FT}(2 \mu \mathrm{M})$

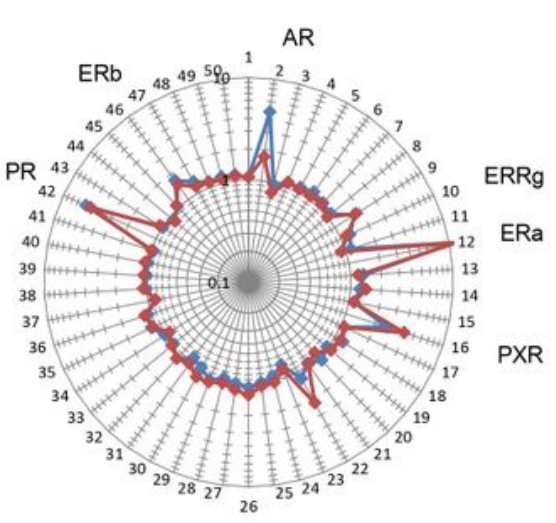

Medvedev et al., Fig. 7

\section{Figure 7}

Please see the Manuscript PDF file for the complete figure caption 


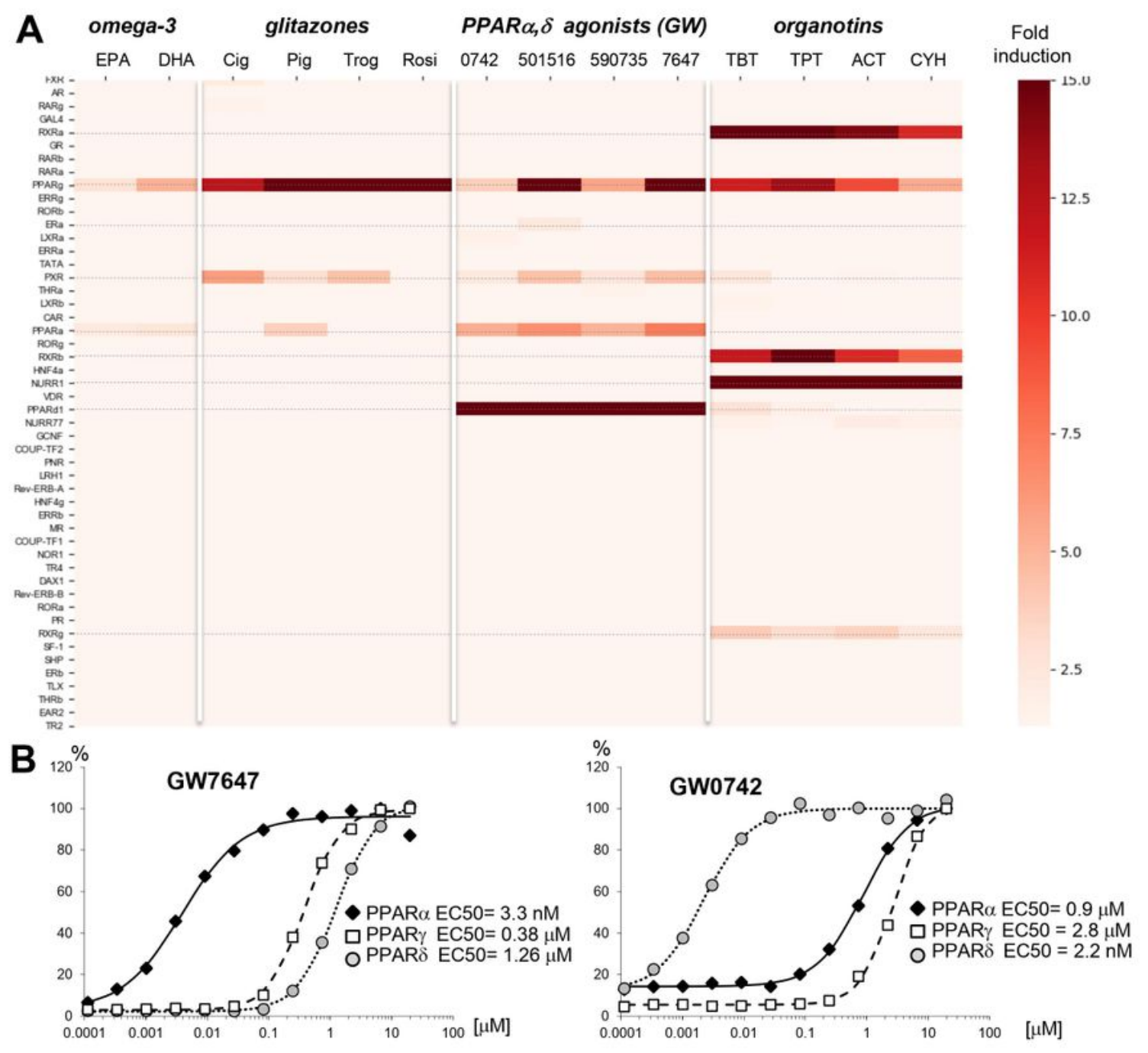

C
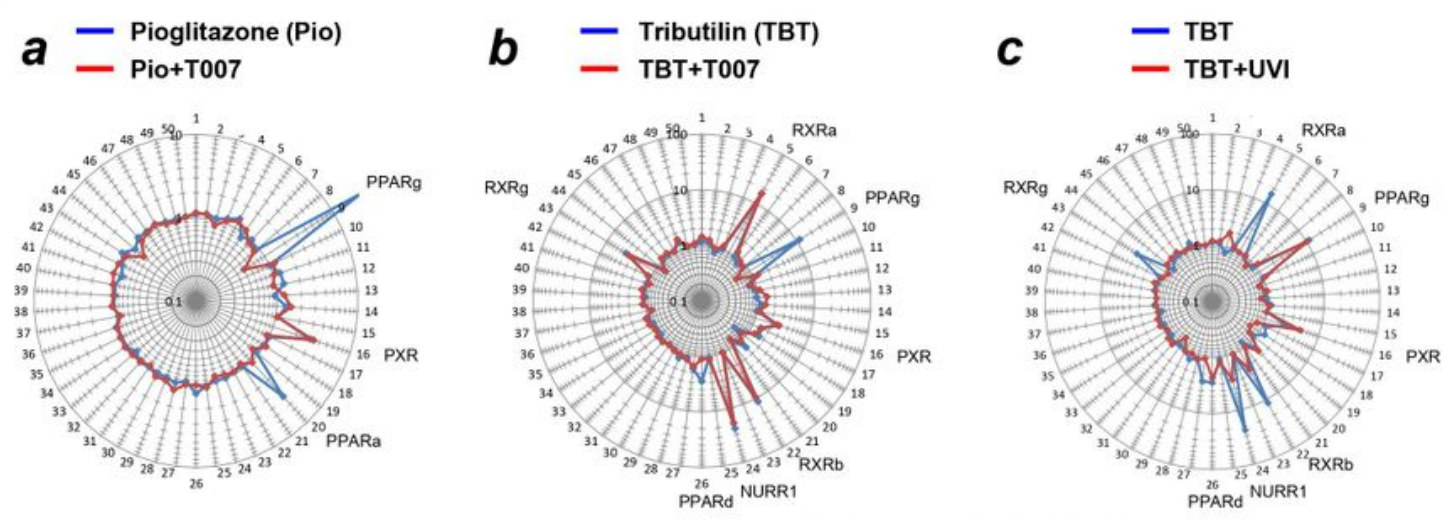

Medvedev et al., Fig. 8

\section{Figure 8}

Please see the Manuscript PDF file for the complete figure caption

\section{Supplementary Files}

This is a list of supplementary files associated with this preprint. Click to download. 
- MedvedevSupplementaryInformationMay072021.pdf 